\title{
EL PRINCIPIO DEL DOBLE EFECTO Y SU RELEVANCIA EN EL RAZONAMIENTO JURÍDICO
}

\author{
THE DOUBLE EFFECT PRINCIPLE AND ITS RELEVANCE TO \\ JURIDICAL INTERPRETATION
}

\section{Alejandro Miranda Montecinos*}

RESUMEN: En este trabajo el autor intenta mostrar la relevancia que le corresponde al principio del doble efecto en el razonamiento práctico general y especialmente en el razonamiento jurídico. Para ello procede del siguiente modo. Primero, estudia la naturaleza del principio como regla para la deliberación moral. Segundo, y con el propósito de ilustrar acerca de las principales situaciones a las que el principio se ha aplicado, ofrece una exposición de su desarrollo histórico. Tercero, presenta los argumentos para justificar la necesidad de acoger el principio del doble efecto, probando que este constituye la única forma no consecuencialista de atribuir responsabilidad por lo efectos de los actos humanos. En cuarto lugar, examina el significado de los requisitos del principio e indica la forma en que ellos deben ser comprendidos. Finalmente, señala algunos ejemplos de diversos ámbitos del Derecho en los que el principio puede ser una útil herramienta para el razonamiento judicial y legislativo.

Palabras clave: principio del doble efecto, voluntariedad indirecta, intención, efectos colaterales, responsabilidad moral y jurídica.

ABSTRACT: In this paper, the author attempts to show the significance of the principle of double effect in general practical reasoning and, especially, in legal reasoning. To this aim, he proceeds in the following way. Firstly, he studies the nature of the principle as a rule to moral deliberation. Secondly, with the purpose of illustrating the main situations in which the principle has been applied, he offers an exposition regarding its historical development. Thirdly, he argues for the necessity of accepting the principle of double effect, proving that it is the only non-consequentialist way to attribute responsibility for the effects of human acts. Fourthly, he examines the principle's requirements and establishes the way in which they have to be understood. Finally, he gives some examples in various legal fields where the principle can be a useful device for judicial and legislative reasoning.

Key words: principle of double effect, indirect voluntariness, intention, side effects, moral and legal responsibility.

\footnotetext{
* Licenciado en Derecho, Pontificia Universidad Católica de Chile. Abogado. Alumno del Programa de Doctorado en Derecho, Universidad de los Andes. Profesor de Filosofía del Derecho en la Universidad de los Andes y en la Pontificia Universidad Católica de Chile. La redacción de este artículo ha contado con la ayuda del Fondo Nacional de Ciencia y Tecnología de la República de Chile, en el marco del Proyecto Fondecyt 1080680, dirigido por el profesor Cristóbal Orrego Sánchez. El autor agradece los comentarios y sugerencias de los profesores Cristóbal Orrego, Antonio Amado y Joaquín García-Huidobro.
} 
Debido a las limitaciones y complejidades del obrar, los hombres se encuentran a menudo enfrentados ante la siguiente situación: necesitan conseguir un determinado fin o efecto bueno, pero se dan cuenta de que la acción por la cual pretenden alcanzarlo también producirá o podrá producir un efecto malo. Cuando ese efecto malo es de cierta importancia, un agente honesto se pregunta si es o no lícito realizar tal acción. Los filósofos moralistas escolásticos, en una tradición de siete siglos, han elaborado un principio de razonamiento práctico que procura precisamente responder dicho interrogante, señalando las condiciones que deben concurrir para la licitud de esa acción.

Este principio, que tiene su origen en distinciones trazadas por Tomás de Aquino, constituía una regla de razonamiento práctico fundamental para los teólogos juristas hispanos de los siglos XVI y XVII, pero no aparece en las obras de los juristas dogmáticos de los siglos posteriores. En los siglos XVIII y XIX su estudio se limita casi exclusivamente a los tratados y manuales de teología moral católica. Sin embargo, a partir de la segunda mitad del siglo XX, con la rehabilitación de la filosofía práctica clásica en el ámbito analítico anglosajón, el principio vuelve a ser estudiado vigorosamente, y ahora también por filósofos moralistas ajenos a la tradición tomista. Estos autores entienden que el principio es una herramienta indispensable en el debate contra las doctrinas éticas que propugnan que un agente es igualmente responsable por todas las consecuencias previsibles de sus acciones (y a veces incluso de sus omisiones), de modo que la determinación de la justicia o injusticia de los actos depende de un cálculo o balance de esas consecuencias. El principio del doble efecto, por el contrario, es reflejo de una teoría moral que reconoce, como salvaguardia de la dignidad de la persona humana, la existencia de ciertas especies de acciones - descritas en términos de sus efectos intencionales inmediatos- que están absolutamente prohibidas con independencia de las ulteriores consecuencias que produzcan.

Como muchos de sus supuestos de aplicación dicen relación con efectos malos o daños jurídicamente significativos, el principio adquiere también una especial relevancia para el razonamiento jurídico. Por eso, desde que los filósofos analíticos renuevan su estudio y muestran su importancia, las distinciones básicas que a él subyacen se comienzan a aplicar generalizadamente en la jurisprudencia del Common Law. El hito de esta recepción jurisprudencial del principio lo marca el caso Vacco vs. Quill (1997), en que la Corte Suprema de los Estados Unidos alude a él por primera vez en el fundamento de un fallo.

Pero a pesar de la profusa literatura jurídica que actualmente se sigue publicando acerca del principio en el ámbito angloamericano, y de la trascendencia que ha adquirido en la jurisprudencia del Common Law, su estudio continúa inexplorado en la literatura jurídica latina actual. Este trabajo constituye, pues, un intento por reinstalar el tema. En él nos proponemos presentar una visión completa y actualizada del principio, para luego mostrar algunos ámbitos del Derecho en los que es importante tenerlo en cuenta.

En una primera parte explicaremos en qué consiste el principio, cómo opera, cuál es su ámbito propio de aplicación y cuál es la manera adecuada de formularlo. En segundo lugar expondremos los hitos más significativos en la historia de su desarrollo, hasta que cristaliza en su formulación más común. En una tercera parte, analizaremos 
los argumentos que se han dado para justificar la relevancia que le cabe al principio en el razonamiento práctico. En cuarto lugar, estudiaremos el significado de sus diversos requisitos. Finalmente, intentaremos mostrar que no solo es moralmente relevante, sino también jurídicamente relevante, y que, por consiguiente, es apto para operar como un principio general de razonamiento jurídico, tanto judicial como legislativo, en cualquier ordenamiento jurídico que haya rechazado el cálculo de consecuencias como un criterio adecuado para determinar la justicia o injusticia de una acción.

\section{NATURALEZA Y FORMULACIÓN DEL PRINCIPIO DEL DOBLE EFECTO}

Se denomina principio, doctrina, regla o razonamiento del doble efecto al principio de razonamiento práctico que sirve para determinar la licitud o ilicitud de una acción que produce o puede producir dos efectos, de los cuales uno es bueno y el otro es malo ${ }^{1}$. El principio recoge algunos de los elementos centrales de la doctrina tomista sobre el acto humano y la responsabilidad moral. En particular, se basa en la relevancia de la distinción entre voluntariedad directa y voluntariedad indirecta. Los seguidores de Tomás de Aquino llamaron "directamente voluntario" a aquello que forma parte del plan de acción del agente, esto es, a lo que él se propone alcanzar como fin de la acción y a lo que busca como medio para conseguir ese fin. Por el contrario, llamaron "indirectamente voluntario" a aquellos efectos de la acción voluntaria, que el agente prevé o debe prever, pero que no busca ni como fin ni como medio, sino que solo acepta, permite o tolera en la medida en que se encuentran ligados a lo que directamente quiere ${ }^{2}$. Siguiendo una terminología equivalente -y hoy más común-, en este trabajo usaremos también la palabra intención para referirnos a la volición del fin y de los medios, y llamaremos efectos colaterales o secundarios a los efectos voluntarios indirectos ${ }^{3}$.

Conforme a esta distinción, la idea principal que subyace al principio del doble efecto es que una persona no es igualmente responsable por todos los efectos malos que se siguen de su acción, sino que existe una diferencia fundamental entre aquellos que intenta y aquellos que solo prevé o debe prever. Por esta razón, el principio cobra toda su impor-

\footnotetext{
${ }^{1}$ Se habla de dos efectos por modo de simplificación, pues, desde luego, puede tratarse de uno, dos o más efectos buenos y uno, dos o más efectos malos.

2 Estos efectos son voluntarios porque el agente, aunque no los quiere simpliciter, prefiere causarlos antes que abstenerse de realizar la acción que los causa y verse privado del bien que mediante ella espera obtener. Para este sentido de lo indirectamente voluntario por parte de Tomás de Aquino, véase $S$. th., I-II, q. 73, a. 8, c.; q. 76, a. 4, c. (en estos pasajes santo Tomás se refiere a efectos imputables ad culpam, pero nada obsta a que la estructura se pueda aplicar a efectos justificados). El Aquinate usa también la expresión "voluntario indirecto" para referirse a lo que se produce como efecto de la omisión de una acción que el agente podía y debía realizar (véase S. th., I-II, q. 6, a. 3, c.; q. 77, a. 7, c.; q. 79, a. 1, c.). En el tomismo posterior es más frecuente el primer sentido, y por eso al principio del doble efecto se lo denomina también "principio del voluntario indirecto" (véase, por ejemplo, PRÜMmER (1931) pp. 44-45).

${ }^{3}$ En la filosofía tomista el término "intención" admite un sentido amplio y uno estricto (véase De malo, q. 2, a. 2, ad 8). El sentido amplio coincide con el que le damos aquí. En sentido estricto, en cambio, se llama intención solo al acto por el cual la voluntad se dirige hacia el propósito último o final de la acción, y se usa el término "elección" para designar la volición de los medios (véase $S$. th., I-II, q. 12, a. 4, ad 3; De ver., q. 22, a. 15, c.; In II Sententiarum, d. 40, q. 1, a. 2, c).
} 
tancia dentro de una doctrina, como la de la tradición moral clásica, para la que existen ciertos efectos malos que, concurriendo determinadas circunstancias o factores medidos por la razón, jamás es lícito intentar (como la muerte de una persona, cuando esa persona es inocente $)^{4}$. En este contexto, el principio supone que si tales efectos malos son intentados serán siempre imputables bajo culpa al agente, mientras que si esos mismos efectos externos son meramente previstos solo le serán imputables ad culpam cuando no ha existido una razón proporcionalmente importante que justifique su acción 5 .

El principio no debe entenderse, entonces, como una regla que establece las condiciones para que sea lícito causar un efecto físicamente malo. Muchas veces es lícito intentar un efecto físicamente malo, porque ese efecto forma parte de un objeto que no es desordenado ${ }^{6}$. Por ejemplo, (i) un marinero puede lícitamente intentar deshacerse de la mercancía, arrojándola al mar, cuando ello es necesario para evitar el naufragio en una tempestad; (ii) un hombre que necesita abrigo puede lícitamente intentar quemar un árbol para obtener calor; (iii) un hombre que necesita alimentarse puede lícitamente intentar matar un animal para comérselo; (iv) un médico puede lícitamente intentar cortar la pierna gangrenada de alguien para evitar que se propague la infección; y (v) un padre puede lícitamente intentar abofetear moderadamente a su hijo cuando es necesario para su corrección y disciplina ${ }^{7}$. Y ninguno de estos casos constituye una "excepción" al principio del doble efecto, pues este tiene lugar solo respecto de aquellos efectos malos que es siempre inmoral intentar, y esos efectos nunca son meros males físicos. Por esto, puede decirse que el principio del doble efecto es un principio de "segundo orden", en el sentido de que supone un razonamiento previo -que puede estar ayudado por otros principios morales- acerca de qué males sería desordenado constituir en objeto de la

\footnotetext{
${ }^{4}$ Véase BOYLE (1991) pp. 475-494.

${ }^{5}$ En sentido moral, un acto humano puede ser imputable como culpable (ad culpam) o como laudable, según sea moralmente malo o moralmente bueno (véase $S$. th., I-II, q. 21, a. 2, c.). Propiamente, la imputabilidad corresponde a los actos humanos -que se especifican por el efecto inmediato que el agente intenta al realizarlos- y no a todos los efectos que de ellos puedan seguirse, pues cabe que algunos efectos no añadan ni bondad ni malicia a la acción (véase $S$. th., I-II, q. 20, a. 5, c.). Cuando en este trabajo usamos la expresión imputable ad culpam, lo hacemos siempre en su sentido moral.

${ }^{6}$ Hablando sensu stricto, nunca se intenta el mal en sí mismo. El agente intenta un objeto (un bien) al cual va unida la privación, ya de un bien físico (mal físico), ya del orden de la razón (mal moral) (véase, por ejemplo, S. th., I-II, q. 79, a. 2, ad 3; I, q. 19, a. 9, c.). Sin embargo, en nuestro contexto podemos hablar correctamente de "intentar" el efecto malo, el daño, la muerte, etc., porque estos males forman parte de la especie de acción elegida. El mismo Tomás de Aquino, de hecho, afirma que "el homicida intenta directamente (intendit directe) el daño del prójimo" (S. th., I-II, q. 73, a. 8, ad 3), y que "el hurto o el homicidio son pecados especiales por causa del daño especial del prójimo que se intenta (intenditur)" (S. th., II-II, q. 43 , a. 3, c.).

7 Y las acciones (i), (ii) y (iii) no son desordenadas precisamente porque en el orden de la naturaleza lo menos perfecto existe para el bien de lo más perfecto (véase $S$. th., II-II, q. 64, a. 1). La (iv) no lo es porque los miembros del cuerpo humano son partes que existen para el bien del todo, y pueden ser cortados cuando ello es necesario para la salud del todo (véase $S$. th., II-II, q. 65, a. 1). Y la (v) no lo es porque la justicia autoriza a inferir daño como castigo o pena (véase $S$. th., II-II, q. 65, a. 2). Por estas mismas razones, el Aquinate puede decir, refiriéndose al caso (iv), que "el sabio artífice induce un mal menor para evitar uno mayor" (S. th., I, q. 48, a. 6, s. c.; véase De malo, q. 1, a. 5, c.), y, refiriéndose a un caso del tipo (v), que "los males de culpa no han de hacerse para que vengan bienes, pero los males de pena se han de inferir por el bien" (S. th., I-II, q. 79, a. 4, ad 4).
} 
voluntad. Una vez que se ha determinado uno de estos casos, el principio entra en escena diciéndonos que ese efecto, que sería siempre inmoral intentar, no es inmoral que se acepte como efecto colateral de una acción necesaria para alcanzar un bien de importancia proporcionada ${ }^{8}$.

Cuando la acción de doble efecto satisface las exigencias del principio, el agente goza de una causa de justificación. Esto quiere decir que esa acción, que en general sería ilícita por causar el efecto malo, deja de serlo en el caso particular, pues se considera que el agente obró razonablemente o con derecho. En otros términos, el efecto malo, que prima facie sería imputable ad culpam al agente por haber sido causado a sabiendas, deja de serle así imputable "consideradas todas las cosas". El principio no opera, pues, como una causa de excusa, ya que el efecto malo no es causado involuntariamente 9 . Tal efecto es considerado en la deliberación que precede a la elección de la acción, y el agente tiene la posibilidad física de evitarlo, absteniéndose de realizar esa acción. Por eso es voluntario. Pero no lo es directamente, porque no es considerado como una razón para la acción, es decir, no es el efecto malo la razón por la que el agente hace la elección que hace $^{10}$. En este sentido, debe decirse que el efecto malo no es querido o buscado por sí mismo, pero sí es deliberadamente aceptado.

El razonamiento del doble efecto puede operar en dos momentos diversos: antes o después de la acción. Cuando opera ex ante, constituye una guía para la deliberación del agente en aquellos casos en que este prevé que la acción que juzga conducente a la consecución de un efecto bueno también producirá o podrá producir un efecto malo. Cuando opera ex post, constituye asimismo un criterio para el juicio sobre la licitud o ilicitud de la acción, pero, a diferencia del caso anterior, en este último el análisis del juzgador tendrá en cuenta no solo los efectos malos previstos, sino también los que el agente debió prever.

La formulación hoy clásica del principio del doble efecto es obra del teólogo moralista Jean-Pierre Gury. La expone en la primera edición de su Compendium theologiae moralis, en los siguientes términos:

"Es lícito poner una causa dirigida a un efecto bueno, aunque de ella se siga un efecto malo, cuando se cumplen las siguientes condiciones, a saber: $1 .^{\circ}$, que el fin

\footnotetext{
8 Si esto se pierde de vista, el principio del doble efecto resulta ininteligible dentro del contexto de la ética tomista, y, además, se hace blanco fácil de innumerables objeciones. En Rossi (1978) p. 239 se le reprocha, por ejemplo, su insuficiencia para explicar todos los casos, pues no sirve para explicar "la legítima defensa del Estado que conmina la pena de muerte o la mutilación de un miembro para salvar todo el cuerpo (también aquí la 'volición' es directa); menos todavía puede explicar el transplante de un órgano de una persona a otra, etc.". Y en el mismo lugar el autor termina su crítica añadiendo: "Que un principio no sirva para todos los casos, no constituye problema; pero sí lo es el que estos casos y otros análogos se resuelvan eliminando una o dos de la condiciones exigidas por dicho principio para la licitud de la acción". Pero esta crítica solo sería pertinente si el principio fuera una regla para juzgar cuándo es inmoral causar un efecto físicamente malo.

9 Sobra la distinción entre causas de justificación y causas de excusa como aquí la usamos, véase FerNÁNDEZ CONCHA (1966b) pp. 321-323 y AUsTin (1970) pp. 175-204.

10 Véase BOyLE (1980) p. 535.
} 
del agente sea honesto; 2. ${ }^{\circ}$, que la causa sea en sí misma buena o al menos indiferente; $3 .^{\circ}$, que el efecto bueno se siga de la causa [al menos] con igual inmediatez que el malo; $4 .^{\circ}$, que el efecto bueno al menos compense al malo" 11 .

El primer requisito exige que el agente no intente el efecto malo como fin del acto. El segundo, que el acto no sea en sí mismo o intrínsecamente malo, i. e., malo por razón de su objeto moral, y, por tanto, por su especie. El tercero apunta a que el efecto malo no sea un medio para alcanzar el efecto bueno, pues de otro modo se violaría el axioma que profiere san Pablo en Romanos 3, 8: "No se debe hacer el mal para que venga el bien". El cuarto, en fin, exige que exista una razón proporcionalmente grave para realizar el acto y no esté el agente obligado a omitirlo por justicia, por razón de su oficio o por caridad ${ }^{12}$.

Desde la obra de Gury, la mayoría de los teólogos moralistas recogen el principio y reproducen, en lo esencial, aunque a veces con un distinto orden, las mismas cuatro condiciones que pedía el autor francés ${ }^{13}$. Ahora bien, como los tres primeros requisitos del principio se ordenan a asegurar que el sujeto no busque el efecto malo ni como fin ni como medio $-i$. e., que no lo quiera directamente- algunos filósofos han propuesto simplificar su enunciado reduciendo los requisitos solo a dos ${ }^{14}$. Como esta precisión nos parece correcta, en lo sucesivo consideraremos que la acción de doble efecto es lícita si se cumplen simultáneamente los dos requisitos siguientes: (i) que el efecto malo no se busque ni como fin ni como medio; y (ii) que exista una razón proporcionalmente grave para aceptarlo. El primer requisito tiene por objeto, entonces, asegurar la bondad de la intención, tanto en el nivel de los fines como en el de los medios, y el segundo apunta a que se cumpla una proporcionalidad, tanto entre la acción y su fin como entre el efecto bueno y el efecto malo. La división de este primer requisito en otros tres, aunque se justifica en el contexto de la finalidad pedagógica de los manuales de moral, es superflua si se tiene en cuenta que la intención del agente incluye el objeto del acto (medio o fin próximo), su fin remoto y todos los demás fines intermedios que el agente juzga necesarios para la realización de sus propósitos o el éxito de su plan ${ }^{15}$.

\footnotetext{
11 "Licet ponere causam ad bonum effectum, quamvis ex ea sequatur effectus malus, si adsint sequentes conditiones: scilicet: $1 .^{\circ} \mathrm{Si}$ finis agentis sit honestus; $2 .^{\circ}$ si causa sit in se bona, vel indifferens; $3 .^{\circ}$ si bonus effectus aeque immediate ac malus ex causa sequatur; $4 .^{\circ}$ si bonus effectus malum saltem compenset" (GURY, 1850, p. 5). A menos que se indique lo contrario en la lista bibliográfica, todas las traducciones que se hacen en este artículo son nuestras.

12 Estas explicaciones no aparecen en la edición de 1850, pero ya pueden encontrarse en la edición hispana del Compendium preparada por J. Ferreres: GURY y FERRERES (1906) pp. 7-8.

13 Véase, por ejemplo, NOLDin (1936) pp. 90-92; LEHMKUHL (1902) pp. 20-21; GÉNiCOT (1909) p. 20; PrÜMmer (1931) p. 46; MerkelbaCh (1935) pp. 165-167; ZALBA (1952) pp. 209 y 211; MAUSBACH y ERMECKe (1971) p. 374; GARCÍA DE HARO (1992) p. 386; FernÁNDEZ (1995) p. 485.

${ }_{14}$ Así piensa, por ejemplo, Joseph Boyle, uno de los principales estudiosos contemporáneos del principio: BOYLE (1980) p. 532. Véase también GALVÃo (2003) pp. 419-440.

15 Véase infra nota 67. Algunos autores proponen mantener tres requisitos. Quienes piensan así formulan el restante (que ocuparía el primer lugar) del modo siguiente: "El acto en sí mismo, es decir, considerado con independencia de sus efectos, debe ser lícito" (véase, por ejemplo, CAVANAUGH (2006) pp. 26-28 y 36). Esta propuesta es correcta si se considera efecto de la acción solo aquel resultado ulterior que ya la
} 
Los teólogos moralistas utilizaron el razonamiento del doble efecto para resolver numerosos problemas de moral. Dándole un uso amplio, lo aplicaron a casos de escándalo pasivo, de cooperación material con el mal ajeno y de uso del mal ajeno para un buen fin $^{16}$, es decir, a situaciones donde la acción cuya moralidad se juzga y el efecto malo se encuentran mediados por una acción voluntaria de otro agente. Estos casos suponen la relevancia moral de la distinción directo/indirecto, pero no corresponden al "caso central" del principio del doble efecto, puesto que en ellos el efecto malo no deriva inmediatamente de la misma acción del sujeto. En este trabajo, nosotros solo nos ocuparemos del caso central del principio, por un doble motivo: primero, porque justificado el caso central se concluye que se justifican los restantes, lo que no ocurre a la inversa; segundo, porque el caso central es el que reviste mayor interés para el Derecho, en cuyo contexto se enmarca el presente estudio.

\section{DESARROLLO HISTÓRICO DEL PRINCIPIO DEL DOBLE EFECTO HASTA SU FORMULACIÓN TRADICIONAL}

El primero que trata explícitamente el problema de la licitud de acciones con doble efecto es Tomás de Aquino. Por esta vía discurre su argumentación en Summa theologiae, II-II, q. 64, a. 7, c., donde expone las razones para probar que no es ilícito a alguien matar a un hombre en defensa de sí mismo. Dice allí santo Tomás que "nada impide que un solo acto produzca dos efectos (duos effectus), de los cuales solo uno sea intencional (sit in intentione) y el otro esté fuera de la intención (praeter intentionem)" 17. Tal cosa es precisamente lo que sucede en el caso de la defensa occisiva, pues "del acto de alguien que se defiende a sí mismo pueden seguirse dos efectos (duplex effectus): uno, la conservación de la propia vida; otro, la muerte del agresor" ${ }^{18}$. Ahora bien, para que la defensa sea lícita es necesario que exista una debida proporción entre la acción y su fin, ya que "un acto que proviene de buena intención puede hacerse ilícito si no es proporcionado al fin (proportionatus fini). Por consiguiente, si uno, para defender su propia vida, usa de mayor violencia que la que conviene, este acto será ilícito"19. Y, por otra parte, debe existir también una proporción entre el efecto bueno y el efecto malo, en el sentido de que el agente debe estar más obligado a conseguir el primero que a evitar el segundo: "No es necesario para la salvación que el hombre omita el acto de defensa moderada para evitar la muerte de otro, porque el hombre tiene que velar más por su vida que por la vida ajena" ${ }^{20}$. En síntesis, la tesis de Tomás de Aquino consiste en que no

supone constituida completamente en su especie. Nosotros, en cambio, consideramos como efecto del acto también al fin próximo o inmediato que define al acto mismo. Sin perjuicio de esto, reconocemos que en ciertos casos puede ser útil mantener este requisito en forma explícita, pues a veces la atención no se centra en el efecto malo que define la acción en general.

16 Véase GURY (1850) pp. 6-7.

17 S. th., II-II, q. 64, a. 7, c.

18 S. th., II-II, q. 64, a. 7, c.

19 S. th., II-II, q. 64, a. 7, c.

20 S. th., II-II, q. 64, a. 7, c. 
se imputa ad culpam la muerte del agresor cuando esta es un efecto praeter intentionem de una acción proporcionada al fin de conservar la propia vida ${ }^{21}$.

Por la presencia de estos elementos, algunos autores consideran a Summa theologiae, II-II, q. 64, a. 7, c., como el texto fundacional del principio del doble efecto ${ }^{22}$. Sin embargo, son muchos también los estudiosos que piensan que este pasaje no contiene una aplicación de dicho principio tal como lo conocemos hoy. Según ellos, la defensa justifica incluso la voluntariedad directa de matar $-i$. e., elegir la muerte del agresor como medio-, lo que estaría precisamente prohibido por una de las condiciones del actual principio ${ }^{23}$. Quienes así leen el texto de santo Tomás, estiman que él está usando la palabra "intención" en su sentido estricto (como volición del fin remoto), y no como comprensiva de la volición de los medios.

Con todo, sin perjuicio de las diferencias de interpretación que existen sobre este difícil pasaje ${ }^{24}$, los requisitos que en él exige el Aquinate para la licitud de una acción de doble efecto constituyen el antecedente, directo o indirecto, a partir del cual los moralistas posteriores elaboran el principio del doble efecto. En este desarrollo histórico le corresponde un papel central a Tomás de Vío, Cayetano, quien, en su comentario de S. th., II-II, q. 64, a. 7, inicia la corriente interpretativa de la defensa occisiva como un caso de voluntario indirecto.

Cayetano (1468-1534) entiende que un efecto es praeter intentionem cuando no es querido ni como fin ni como medio:

\footnotetext{
${ }^{21}$ Además de este lugar, existen otros donde Tomás de Aquino también admite que un buen fin justifica la realización de acciones lícitas en sí mismas de las que previsiblemente se pueden seguir efectos malos, pero la mayoría de ellos se refieren a casos de escándalo pasivo (véase $S$. th., II-II, q. 43, a. 1, ad 4; a. 3, a. 7 y a. 8), de cooperación material con el mal ajeno (véase $S$. th., II-II, q. 169, a. 2, ad 4; III, q. 80, a. 6) o de uso del mal ajeno para un buen fin (véase $S$. th., II-II, q. 78, a. 4; De malo, q. 13, a. 4, ad 18 y ad 19), que, como hemos dicho, no corresponden al caso central del principio del doble efecto.

22 Véase MANGAN (1949). Es significativo también que, luego de formular el enunciado del principio, GURY (1850) p. 5 hace una referencia expresa a S. th., II-II, q. 64, a. 7.

23 Véase Alonso (1937); MATthews (1999); LONG (2003); LONG (2007) pp. 39-63; ReICHBERG (2005). La idea de que la defensa occisiva justifica la voluntariedad directa de matar es mayoritaria entre los comentadores escolásticos de Tomás de Aquino: véase, por ejemplo, VITORIA, Commentarium in secundam secundae, q. 64, a. 7; AZPILCUETA, Enchiridion sive manuale confessariorum et poenitentium, c. 15, n. 2; SOTO, De iustitia et iure, 1. 5, q. 1, aa. 2 y 8; NAVARRA, De ablatorum restitutione in foro conscientiae, 1. 2, c. 3, pars 3, dubit. 2, n. 337 ss.; Toledo, In Summam theologiae S. Thomae Aquinatis enarratio, II-II, q. 64, a. 7; Molina, De iustitia et iure, tr. 3, disp. 11, n. 4; AZOR, Institutionum moralium, pars 3, 1. 2, c. 1; VÁZQUeZ, Opuscula moralia, tr. De restitutione in foro conscientiae, c. 2, par. 1, dub. 6, nn. 15-17; LESSIO, De iustitia et iure, 1. 2, c. 9, dubit. 8, n. 53; BECANUS, De iustitia et iure, q. 64 D. Thomae, q. 6, conc. 2; LugO, Disputationes scholasticae et morales, tr. De justitia et jure, disp. 10, sec. 6, n. 148 ss. (Las obras de los escolásticos anteriores a 1800 las cito según sus propias subdivisiones).

${ }^{24}$ Junto con las interpretaciones que niegan que $S$. th., II-II, q. 64, a. 7, c., contenga el principio del doble efecto porque la legítima defensa autorizaría a más, hay otras que niegan lo mismo basándose en que autorizaría a menos. En CAVANAUGH (1997) se afirma que el Aquinate tiene en mente el caso en que el agredido realiza una acción que implica el riesgo de matar al atacante (i. e., la muerte es una consecuencia posible), y no una acción que le causará la muerte como un efecto previsto con seguridad por ser inevitable. El autor apoya su lectura en dos argumentos: $1 .^{\circ}$, que santo Tomás, en el ad 4 , habla de una acción de la que a veces (quandoque) se sigue el homicidio, y 2..$^{\circ}$, que la expresión praeter intentionem es usada por el Aquinate, por regla general, para referirse a efectos que no se siguen de la acción con seguridad.
} 
“... de dos modos se puede referir la occisión de otro a la conservación de la propia vida: primero, como medio para conseguir el fin; segundo, como consecuencia de la necesidad del fin. Y como se dice en el texto importa mucho distinguir uno del otro. Pues tanto el fin como el medio para el fin caen bajo la intención, como es patente en el médico que intenta la salud a través de una medicina o dieta. Pero lo que se sigue de la necesidad del fin no cae bajo la intención, sino que surge praeter intentionem, como es patente en la debilidad del enfermo producida por la medicina" 25 .

De este modo, según Cayetano, la persona pública, al ordenar la muerte del enemigo o del malhechor como medio subordinado al fin del bien común, mata per se, mientras que "el privado no intenta matar para salvarse, sino que intenta salvarse sin renunciar a su defensa, aunque de ella se siga la muerte de otro. $\mathrm{Y}$ así este no mata sino per accidens" 26 .

Conforme a esta lectura, en $S$. th., II-II, q. 64, a. 7, c., ya se encuentran presentes los dos requisitos centrales del doble efecto: (i) el efecto malo (la muerte del agresor, la debilidad del enfermo) no debe ser querido ni como fin ni como medio (debe ser praeter intentionem), y (ii) debe haber una razón proporcionalmente grave para realizar el acto (conservar la propia vida, recobrar la salud) respecto de la cual ese acto debe ser necesario. Por intermedio de Cayetano, entonces, la relevancia de la distinción entre efectos intentados y efectos praeter intentionem (entendidos estos como efectos no queridos ni como fin ni como medio) pasa a la tradición posterior y es asumida incluso por quienes no compartían su explicación de la legítima defensa.

Francisco de Vitoria (1483-1546), que fue un asiduo lector de Cayetano, recoge la distinción entre matar per se (o ex intentione) y matar per accidens (o praeter intentionem) y recurre a ella, en su tratamiento del ius in bello, para justificar la aceptación de bajas civiles como efecto colateral de acciones bélicas de suyo lícitas, caso que pronto se convertirá en el ejemplo más común de aplicación del principio del doble efecto. Enseña Vitoria que nunca es lícito matar a los inocentes per se et ex intentione, "mas, per accidens, algunas veces es lícito matar inocentes incluso a sabiendas, como cuando se ataca justamente una fortaleza o una ciudad, en la cual consta que hay muchos inocentes, y no pueden emplearse máquinas de guerra, ni armas arrojadizas, ni ponerse fuego a los edificios, sin que padezcan tanto los inocentes como los culpables" 27 . Asimismo, Vitoria reconoce la exigencia de una debida proporcionalidad. Por un lado, insiste en la necesidad de una proporción entre el efecto bueno y el efecto malo, y por eso añade que "si para conseguir la victoria principal en una guerra, representa poco el atacar una fortaleza o una ciudad en que hay guarnición enemiga, y hay allí muchos inocentes, no

25 Cayetano, Commentarium in Summa S. Thomae, II-II, q. 64, a. 7. Cayetano comenzó a escribir su comentario a la Summa en 1507 y lo concluyó hacia 1522.

${ }^{26}$ CaYetano, Commentarium in Summa S. Thomae, II-II, q. 64, a. 7.

27 Vitoria, De indis posterior, sive De jure belli hispanorum in barbaros, n. 37. Esta relección fue leída en 1539. 
parece lícito que para combatir a unos pocos culpables se pueda matar a muchos inocentes" 28 . Por otro, deja en claro que la acción de la que se sigue el efecto malo debe ser necesaria para alcanzar el efecto bueno: “... nunca parece lícito matar inocentes, incluso per accidens et praeter intentionem, sino cuando la guerra justa no puede desenvolverse de otro modo" 29 .

Ahora bien, también hubo quien vio el principio en el mismo texto de santo Tomás sobre la legítima defensa. Este es el caso de Domingo Báñez (1528-1604), que interpreta $S$. th., II-II, q. 64, a. 7, c., al modo de Cayetano, es decir, entiende que un efecto es praeter intentionem cuando no es querido ni como fin ni como medio: "Santo Tomás nunca dice que la occisión del hombre es un medio lícito para la conservación de la vida por parte de una persona privada, sino que la misma defensa es medio para la conservación de la vida, y que la occisión es un efecto que se sigue per accidens y praeter intentionem" 30 . Báñez se da cuenta del alcance que la distinción entre efectos intentados y efectos praeter intentionem tiene para el razonamiento práctico, y por eso añade que "esta doctrina es muy necesaria para otras materias morales" 31 . Además, comprende que la doctrina que él reconoce en este pasaje es una doctrina general que tiene por cometido determinar "en qué caso el hombre está obligado a abandonar una acción, de otro modo buena, para que de ella no se siga un efecto malo, o en qué caso es lícito proseguir la acción buena aun cuando de ella se siga algún efecto malo" 32 . Báñez admite que esto exige gran trabajo, pero se anima a proponer dos reglas universales para juzgar los casos de esta naturaleza:

"Primero: cuando la acción en sí misma buena, de la cual se sigue algún efecto en sí mismo ilícito, o nocivo respecto de otro, me es sin embargo necesaria para la conservación de aquello a lo que tengo derecho, me es lícito perseverar en aquella buena acción, con tal de que el efecto que de ella se sigue per accidens no sea notablemente nocivo para el bien común. Y mucho más será lícito persistir en aquella acción cuando ella promueve el bien común. Este principio se verifica en la acción por la que se defiende la propia vida y de la cual se sigue la occisión del agresor [...]. Y se verifica también principalmente en la guerra justa, cuando las tropas, peleando contra la ciudad enemiga, matan inocentes per accidens y praeter

\footnotetext{
28 VITORIA, De jure belli hispanorum in barbaros, n. 37.

${ }^{29}$ Vitoria, De jure belli hispanorum in barbaros, n. 37. Véase también la "relección" De homicidio (leída en 1529), n. 37, donde Vitoria justifica, apelando a las mismas distinciones, las acciones de Sansón y Eleazar (narradas, respectivamente, en Jueces 16, 22 ss. y I Macabeos 6, 43 ss.). Tomás de Aquino, por el contrario, siguiendo una explicación que venía de san Agustín, justifica como lícita la acción de Sansón afirmando que actuó por una inspiración del Espíritu Santo (véase S. th., II-II, q. 64, a. 5, ad 4; Collationes in decem praeceptis, a. 7).

30 BÁÑEZ, Decisiones de iure et iustitia, II-II, q. 64, a. 7, dubit. 5. (La primera edición de esta obra es de 1594).

31 BÁÑEZ, Decisiones de iure et iustitia, II-II, q. 64, a. 7, dubit. 5. Véase también BÁÑEZ, Commentaria in secundam secundae Angelici Doctoris D. Thomae: quibus, quae ad fidem, spem, et charitatem spectant; clarissime explicantur, II-II, q. 40, a. 1, dubit. 11, conc. 2. (La primera edición es de 1584).

32 BÁNEZ, Decisiones de iure et iustitia, II-II, q. 64, a. 7, dubit. 5.
} 
intentionem. [...] Segundo: cuando aquella acción, que es buena, o ciertamente no es en sí misma mala, no me es necesaria, sino más bien poco útil, y si por cesar en ella poco o ningún daño me sucede, y por otra parte se sigue de ella algún daño notable al prójimo, estoy obligado a cesar en aquella acción, ya por caridad, ya por justicia" 33 .

Hemos transcrito este texto porque tiene el mérito de ser, hasta donde sabemos, el primer intento por formular la doctrina del doble efecto como un principio general. Según el planteamiento de Báñez, como se ve, es lícito realizar una acción de la que se sigue un efecto malo si se cumplen los siguiente requisitos: (i) que ese efecto malo sea per accidens o praeter intentionem; (ii) que la acción sea en sí misma buena; (iii) que sea necesaria para conservar o alcanzar un bien al cual se tiene derecho (o el bien común); y (iv) que el efecto malo no sea un daño notable para el bien común o para el prójimo en relación (proporción) con la importancia del bien intentado. Ya están aquí presentadas, indudablemente, todas las exigencias tradicionales del principio, aunque Báñez no haya hecho el trabajo de enumerarlas una a una.

Francisco Suárez (1548-1617), que aborda el problema del ius in bello en forma muy similar a la de Vitoria, afirma, al igual que él, que "por ninguna razón se puede matar per se a los inocentes" 34 , pero "se puede per accidens cuando es necesario para conseguir la victoria" 35 . Por esto, acciones bélicas como los incendios de ciudades y la destrucción de fortalezas, que necesariamente van unidas con la muerte de inocentes, son lícitas cuando son indispensables para lograr la victoria. Suárez se detiene a dar razón de esta distinción: "En efecto, el que tiene derecho al fin de la guerra, hablando per se, tiene derecho a esos medios: pues en este caso la muerte de los inocentes no es per se intentada, sino que se sigue per accidens, y por eso no se estima voluntaria, sino permitida por el que hace uso de su derecho en tiempo de necesidad"36. Y a continuación generaliza el principio: "Del mismo modo, la mujer que tiene un hijo en su útero puede usar una medicina necesaria para su vida, aun cuando sepa que de esto se seguirá como consecuencia la muerte del hijo" 37 . Desde luego, para que se pueda apelar a dicha regla, Suárez también exige, como sus predecesores, que se cumpla la proporcionalidad entre ambos efectos, de ahí que "cuando tal medicina no es absolutamente necesaria para la vida de la madre, sino tal vez solo para fortalecer su salud, entonces debe ser preferida la vida de la prole" 38 .

\footnotetext{
33 BÁÑEZ, Decisiones de iure et iustitia, II-II, q. 64, a. 7, dubit. 5.

34 SUÁREZ, Commentaria in secundam secundae divi Thomae, scilicet de fide, de spe et de charitate disputationes, tr. 3, disp. 13, sec. 7, n. 15. (La primera edición se publicó póstumamente, en 1621).

35 SuÁreZ, Commentaria in secundam secundae divi Thomae..., tr. 3, disp. 13, sec. 7, n. 15.

36 SUÁREZ, Commentaria in secundam secundae divi Thomae..., tr. 3, disp. 13, sec. 7, n. 17.

37 SUÁREZ, Commentaria in secundam secundae divi Thomae..., tr. 3, disp. 13, sec. 7, n. 17.

38 SuÁrez, Commentaria in secundam secundae divi Thomae..., tr. 3, disp. 13, sec. 7, n. 19. Juan Azor (1535-1603) y Tomás Sánchez (1550-1610) justifican este caso del mismo modo. Sánchez cita S. th., II-II, q. 64, a. 7, c. como apoyo de su doctrina. Véase AZOR, Institutionum moralium, pars 3, 1. 2, c. 3; SÁNCHEZ, De sancto matrimonii sacramento disputationum, 1. 9, disp. 20, nn. 13-15.
} 
Juan de Lugo (1583-1660), siguiendo el mismo esquema de sus contemporáneos, niega la licitud de la occisión directa o intencional del inocente, pero agrega que "matar al inocente de un segundo modo, indirectamente (indirecte) y praeter intentionem, es lícito algunas veces por una causa gravísima, en lo que todos convienen"39. Para mostrarlo, ofrece el ejemplo ya clásico: "El ejemplo común es, cuando en la guerra, para obtener la victoria y expugnar a los enemigos, es necesario dirigir el tormentum hacia la fortaleza, en la que algunos inocentes han de morir al mismo tiempo que los nocentes" ${ }^{\prime \prime}$. Y afirma expresamente que la muerte prevista se dice no intentada cuando no es intentada como fin ni elegida como medio ${ }^{41}$. Lugo también comprende que está en presencia de una regula de carácter general. En efecto, aunque la trata al discutir la licitud de acciones de las que se sigue la muerte de un inocente, inmediatamente sugiere su aplicación en otras materias ${ }^{42}$. Y deja constancia de que "existe dificultad en la aplicación de esta regla a los casos particulares" 43 .

Un vez que los ejemplos de aplicación del principio ya se han generalizado, la mayoría de los grandes teólogos lo incorporan en sus obras. Juan de Santo Tomás (Juan Poinsot: 1589-1644) ${ }^{44}$, los salmanticenses ${ }^{45}$, y, en el siglo XVIII, Charles-René Billuart $(1685-1757)^{46}$ y san Alfonso María de Ligorio (1696-1787) ${ }^{47}$, constituyen notables ejemplos. En el siglo XIX, como ya hemos dicho, Jean-Pierre Gury (1801-1866) expone por primera vez el principio con la enumeración de los cuatro requisitos hoy tradiciona-

${ }^{39}$ Lugo, Disputationes scholasticae et morales, tr. De justitia et jure, disp. 10, sec. 5, n. 123. (La primera edición es de 1642)

${ }^{40}$ LUGO, De justitia et jure, disp. 10, sec. 5, n. 123. El tormentum era una máquina de guerra que arrojaba proyectiles, como una catapulta.

41 Véase Lugo, De justitia et jure, disp. 10, sec. 5, n. 125.

42 Véase Lugo, De justitia et jure, disp. 10, sec. 5, n. 126.

43 Lugo, De justitia et jure, disp. 10, sec. 5, n. 124.

${ }^{4}$ Véase Poinsot, Cursus theologicus, tr. De bonitate et malitia actuum humanorum, disp. 11, a. 6, nn. 3143. (La primera edición se publicó póstumamente, en 1645). Comentando S. th., I-II, q. 20, a. 5, Juan de Santo Tomás menciona una serie de acciones lícitas que producen efectos malos previstos. No obstante, con la sola excepción de la defensa occisiva, no se trata de situaciones que correspondan a lo que aquí hemos denominado "caso central" del principio, sino de efectos malos que suponen la intervención de la voluntad de otro agente (ver los nn. 37 y 38). Por esta razón, y por todo el desarrollo que hemos visto en autores muy anteriores a él, es difícil concordar con la influyente afirmación de GHOOS (1951) según la cual todos los elementos que conforman el principio del doble efecto no están formalmente presentes sino hasta Juan de Santo Tomás.

45 El principio está presente tanto en el Cursus theologicus dogmático como en el Cursus theologicus moral. En el primero es desarrollado en el tratado 13, De vitiis et peccatis (publicado en 1658), escrito por Domingo de Santa Teresa (1604-1660). En el segundo se lo estudia en el tratado 20, De principiis moralitatis (publicado en 1714), que fue escrito por Sebastián de San Joaquín (c. 1672-1718).

46 Véase BILLUART, Summa S. Thomae hodiernis academiarum moribus accommodata, sive Cursus theologiae, tr. De actibus humanis, diss. 1, a. 1; tr. De jure et justitia, diss. 8, a. 13. Estos pasajes de Billuart constituyen una de las tres fuentes explícitamente citadas por Gury luego de enunciar el principio (las otras dos son S. th., II-II, q. 64, a. 7 y el tratado De iustitia et iure de Joseph Carrière [1795-1864]). Con todo, el principio está expuesto con más detalle en tr. De jure et justitia, diss. 10, a. 4, y esta debe de haber sido la fuente principal de Gury, pues su enunciado del principio reproduce a la letra varias expresiones que aquí profiere Billuart. (La obra de Billuart se publicó entre 1746 y 1751).

47 Véase Ligorio, Theologia moralis, 1. 5, tr. praeamb., a. 2, n. 14. (La primera edición es de 1753). 
les, en la primera edición de su Compendium theologiae moralis $(1850)^{48}$. Desde Gury, el principio está presente en todos los manuales clásicos de teología moral católica ${ }^{49}$ y también en numerosos documentos del magisterio de la Iglesia católica ${ }^{50}$.

\section{JUSTIFICACIÓN DEL PRINCIPIO DEL DOBLE EFECTO. LAS PROHIBICIONES ABSOLUTAS COMO GARANTÍA DEL BIEN HUMANO}

Hemos visto que, al momento de dar razón de la doctrina del doble efecto, autores como Báñez o Suárez pusieron el énfasis en la existencia de un derecho a conseguir el fin. El derecho al fin, crea el derecho a los medios de suyo lícitos. Por eso, aunque el medio conlleve efectos colaterales malos, puede igualmente ser lícito. Los teólogos moralistas posteriores recogieron, en lo esencial, este mismo argumento. San Alfonso María de Ligorio, por ejemplo, justifica la distinción directo/indirecto diciendo que el agente no está obligado, por la previsión del efecto malo, a omitir una acción a la que tiene derecho, pues "quien usa de su derecho no se dice causa del efecto no intentado y que se ha seguido per accidens" 51 . Y Jean-Pierre Gury, luego de enunciar el principio, añade que, supuesta la bondad del fin y de los medios, no concurre en la acción ninguna fuente posible de malicia moral: la acción no se vuelve ilícita por la previsión del efecto malo, ya que "en la hipótesis, el efecto malo es al menos compensado por el bueno. Ahora bien, cada uno tiene derecho a obtener un buen fin por medio de una causa honesta, donde el mal no supera al bien, pues el derecho al fin crea el derecho a los medios" 52 .

Pero estas razones, que pueden haber bastado en el contexto histórico en que tales autores escribieron ${ }^{53}$, hoy en día se nos presentan como insuficientes. En efecto, ellas parecen apuntar, más bien, a mostrar que un efecto colateral malo solo se justifica por una razón proporcionada, y no a mostrar que una razón proporcionada solo justifica un efecto colateral malo pero nunca un medio malo. Si dichos argumentos se ordenan a probar esto último, entonces no lo consiguen ${ }^{54}$. Desde que toman fuerza las teorías éticas que cifran la bondad o malicia de la acción en un balance de todas sus consecuen-

48 Véase GuRY (1850) p. 5. Para la historia del principio desde la sistematización de Gury hasta su interpretación proporcionalista por parte de Peter Knauer, véase KACZOR (1998).

49 Véase supra nota 13, y además: VERMEERSCH (1922) pp. 118-119 y LOIANO (1934) pp. 46-48.

50 Véase, por ejemplo, los números 1737, 2279, 2258, 2263, 2268, 2271, 2296, 2297, 2322 y 2370 del Catecismo de la Iglesia Católica; el Discurso de Pío XII al IX Congreso de la Sociedad Italiana de Anestesiología, de 24 de febrero de 1957, y, sobre todo, el Discurso del mismo pontífice al VII Congreso Internacional de Hematología, de 12 de septiembre de 1958.

${ }^{51}$ LigOrIO, Theologia moralis, 1. 5, tr. praeamb., a. 2, n. 14.

52 GURY (1850) p. 6.

53 Todos estos autores escriben bajo el supuesto no controvertido de que existen actos malos de suyo (por su especie), cuya realización nunca es lícita.

54 Como se afirma en BOYLE (2004) p. 56, la ausencia de una argumentación más profunda por parte de los antiguos moralistas católicos quizá se debe a que vieron la significación de la distinción como obvia, en virtud de la analogía que ella guarda con lo que sucede en la acción creadora divina. Dios, en efecto, solo intenta el bien, pero permite los males anejos a las naturalezas que crea: véase, p. ej., S. th., I, q. 19, a. 9, ad 3; q. 22, a. 2, ad 2; q. 48, a. 2, ad 3; q. 49, a. 2, c.; De ver., q. 5, a. 4, ad 10. 
cias previsibles, o en los fines remotos que con ella el agente intenta promover, la doctrina del doble efecto debe ser justificada con más precisión.

La pregunta por la justificación del principio es, propiamente, la pregunta por la justificación de su distinción central: aquella que existe entre lo voluntario directo y lo voluntario indirecto. Se debe mostrar cuál es la razón de que un agente no sea igualmente responsable por todos los efectos de su acción que previó o debió prever. En otras palabras, hay que demostrar por qué un agente es siempre moralmente culpable si intenta determinados efectos malos, sin importar la trascendencia del bien que pretende conseguir, mientras que no siempre es moralmente culpable por causarlos a sabiendas pero sin intención, sino que en este caso puede estar justificado si su acción se ordenaba a la consecución de un bien de importancia proporcionada.

El argumento principal para aceptar que la distinción entre lo voluntario directo y lo voluntario indirecto (o entre fines-y-medios y efectos colaterales, o entre intención y mera aceptación) es relevante para el razonamiento práctico es este: ella es necesaria para la coherencia de cualquier doctrina moral que admita la existencia de prohibiciones morales absolutas ${ }^{55}$. En efecto, si tales prohibiciones se dirigen hacia acciones que causan determinados efectos malos, solo pueden recaer sobre aquellas que los causan intencionalmente, de lo contrario serían imposibles de cumplir. Esto se debe a que es siempre posible para el agente abstenerse de intentar dichos efectos malos, mientras que, por el contrario, no le es siempre posible evitar causarlos como efectos colaterales. Ahora bien, una norma moral que no puede ser cumplida, no puede tampoco ella cumplir su función de dar una dirección coherente al razonamiento práctico ${ }^{56}$.

Que muchos efectos malos que sería inmoral intentar acompañan inevitablemente a la generalidad de nuestras acciones, puede verse claramente si se pone atención en acciones tan básicas y necesarias como respirar, comer o beber. Todas ellas conllevan efectos colaterales que amenazan la vida y la salud, como la ingestión de toxinas, bacterias, virus, alérgenos o parásitos. No puede, pues, haber una obligación absoluta de evitarlos. De lo contrario, deberíamos también privarnos del uso de medicamentos o de someternos a intervenciones quirúrgicas, actividades que siempre provocan efectos malos que podemos prever incluso con certeza ${ }^{57}$. Pero, en realidad, ni siquiera el recurso a la inacción sería una solución al problema, pues la decisión deliberada de no actuar para evitar los malos efectos colaterales provocaría otros peores. En síntesis, la materialidad del mundo, la complejidad de los vínculos causales y las limitaciones propias de nuestro obrar nos fuerzan a aceptar la importancia de la distinción.

\footnotetext{
55 Véase ANSCOMBE (2001a) p. 256. La idea de Elizabeth Anscombe parece ser que si negamos la relevancia de la distinción directo/indirecto una doctrina de prohibiciones morales absolutas sería incoherente, puesto que produciría prescripciones contradictorias. Siendo así, solo podríamos salir de la perplejidad mediante el cálculo de consecuencias.

56 Véase Finnis (1991a) p. 63; Finnis (1991b) p. 71; BOYLE (1991) pp. 486-487. En la exposición del argumento sigo hasta aquí muy de cerca a estos autores. En lo sucesivo tengo también en cuenta las observaciones críticas que se les formula en ANDERSON (2007) pp. 265-266.

57 Véase ANDERSON (2007) p. 266.
} 
Pues bien, como causar efectos colaterales malos es inevitable, el único criterio posible para establecer qué clases, tamaños o cantidades de efectos colaterales malos es lícito aceptar no puede ser otro que el de la mayor o menor importancia de las razones que el agente tenía para actuar. Con excepción de esta "proporción” entre los bienes que se intentan y los males que se toleran, cualquier criterio sería arbitrario ${ }^{58}$.

El mismo argumento puede expresarse diciendo que la distinción directo/indirecto es necesaria para la existencia de "acciones intrínsecamente malas", que son precisamente aquello que prohíben las normas absolutas. La razón de esto es que no puede admitirse la existencia de especies de acciones intrínsecamente malas sin que exista un criterio para distinguir o separar el efecto que define esa acción respecto de cualquier otro efecto malo que, en determinadas circunstancias, ella pueda causar. Pero el efecto que define la especie de la acción, por la razón que ya hemos visto, solo puede ser aquel que el agente intenta. Por ello, para los filósofos clásicos las acciones intrínsecamente malas son siempre especies de acciones definidas o descritas en términos intencionales. Aristóteles, por ejemplo, afirma explícitamente estas ideas. Por un lado, sostiene que existen especies de acciones malas en sí mismas (como el adulterio, el robo y el homicidio), cuya realización es, por ello, siempre ilícita ${ }^{59}$. Por otro, afirma que los nombres que designan especies de acciones ( $v$. $g r$, robo, adulterio, ultraje, homicidio) significan no solo el comportamiento físico que produce determinados efectos exteriores, sino también, y principalmente, la intención con que dichas acciones se realizan ${ }^{60}$. Y entiende que intentar consiste en hacer algo en vista de algo (héneká tou) ${ }^{61}$. Tomás de Aquino, por su parte, también hace suya la tradición, pagana y cristiana, de que existen actos humanos que en sí mismos o de suyo implican un desorden, por lo que no es lícito hacerlos por ningún fin, por muy bueno que pretenda ser, ni en ninguna circunstancia, por muy excepcional que parezca ${ }^{62}$. Asimismo, desarrolla en múltiples oportunidades el principio de que los actos humanos se especifican por lo que en ellos se intenta ${ }^{63}$, que para él no es más que la concreción, en el orden moral, del principio general de que los actos se especifican por sus objetos ${ }^{64}$, puesto que el fin $-i$. e., lo intentado- es el objeto de la voluntad $^{65}$. El Aquinate precisa, además, que bajo el término intención, en este sentido,

\footnotetext{
58 Véase ANDERSON (2007) p. 266.

59 Véase ARISTÓteles, Ética a Nicómaco, II, 6, 1107a8-17; Ética eudemia, II, 3, 1221 b20 ss.

60 Véase ARISTÓteles, Retórica, I, 13, 1374a1-18. Por eso, "un golpe no siempre equivale a un ultraje, sino solo si se golpea con el propósito de insultar al hombre golpeado o de satisfacerse quien golpea. Tampoco tomar una cosa sin el conocimiento del dueño equivale siempre a un robo, sino solo si se toma con la intención de retenerla en perjuicio de su dueño" (1374a13-17. La cursiva es nuestra). Esto se debe a que "es la intención (proaíresis) lo que constituye la malicia y el acto injusto" (1374a11-12).

61 Véase ARISTÓTELES, Retórica, I, 13, 1374a12-14.

62 "Lo que es malo en sí (secundum se malum) ningún buen fin hace lícito, como consta por Agustín en su libro Contra mendacium, y por el Filósofo en el libro II de la Ética" (S. th., II-II, q. 64, a. 2, 3 a.); "Aquello que es pecado por su género (peccatum ex genere), no es lícito hacerlo por ningún fin bueno, según aquello de Romanos III, 8” (De malo, q. 15, a. 1, 5 a.). Véase, además, S. th., II-II, q. 110, a. 3, c. y ad 4.

${ }^{63}$ Véase, por ejemplo, S. th., II-II, q. 64, a. 7, c.; II-II, q. 150, a. 2, c.

${ }^{64}$ Véase, por ejemplo, De malo, q. 1, a. 1, ad 4; Contra gentiles, III, c. 139, n. 2.

65 Véase, por ejemplo, S. th., I, q. 48, a. 1, ad 2; II-II, q. 4, a. 3, c.
} 
caben tanto los fines como los medios ${ }^{66}$, ya que en el orden de los medios para el fin todos los medios son también fines (fines intermedios) ${ }^{67}$. Más aún, añade que es precisamente el más próximo de estos fines el que confiere al acto su primera especie ${ }^{68}$. A este fin próximo lo llama también objeto ${ }^{69}$ y lo caracteriza como aquello sobre lo que versa el acto de la elección ${ }^{70}$. Por el contrario, todos los efectos que están fuera de la intención (praeter intentionem) son, desde el punto de vista moral, per accidens, y no entran en la determinación de la especie de la acción ${ }^{71}$.

El argumento anterior nos conduce, desde luego, a preguntarnos por qué tendríamos que aceptar, con Aristóteles, san Pablo, san Agustín, santo Tomás y otros muchos, la existencia de especies de acciones intrínsecamente malas cuya realización está prohibida sin excepción. La razón es que este es el único sistema coherente de establecer la responsabilidad del hombre por sus acciones. En efecto, si el hombre no es responsable primaria y principalmente por los efectos inmediatos que intenta con sus acciones, solo cabe que lo sea, o por todos los efectos previstos o previsibles que de ellas se siguen, o por los fines que remotamente intenta al realizarlas. Pero estas dos últimas opciones presentan problemas insuperables. En primer lugar, una teoría que considera al hombre como igualmente responsable de todas las consecuencias previsibles de su obrar, anula, en realidad, el concepto mismo de responsabilidad, pues, como ha escrito Spaemann, "[q]ue alguien sea responsable de algo significa que se le exonera de otras consecuencias de su actuar. La responsabilidad de un médico por la salud de su paciente quedaría destruida si al mismo tiempo no exonerase al médico de todas las cosas malas que ese paciente pueda hacer con su salud"72. En segundo lugar, ambas implican que la responsabilidad moral solo se puede establecer en virtud de alguna forma de cálculo o ponderación de bienes y males. Pero muchos autores han demostrado de manera contundente la inviabilidad de cualquier doctrina que apele a este método como forma válida para

66 "La intención, como se ha dicho, no solo es del fin último, sino también del fin intermedio (finis medii). Ahora bien, se puede intentar al mismo tiempo un fin próximo y otro último, como preparar la medicina y recobrar la salud" (S. th., I-II, q. 12, a. 3, c.).

${ }^{67}$ Véase De veritate, q. 5, a. 4, c.; In II Physicorum, 1. 5, n. 6; In V Metaphysicorum, 1. 2, n. 9; Contra gentiles, III, c. 2, n. 5.

68 “... el mismo acto en número, según que de una vez sale del agente, no se ordena sino a un fin próximo, del cual toma la especie, pero puede ordenarse a muchos fines remotos, de los cuales uno es fin del otro" (S. th., I-II, q. 1, a. 3, ad 3). Véase también S. th., I-II, q. 60, a. 1, ad 3; II-II, q. 11, a. 1, ad 2; II-II, q. 66, a. 4, ad 2; De malo, q. 8, a. 1, ad 14; De virtutibus in communi, q. 1, a. 12, ad 1.

69 “... el fin es doble: próximo y remoto. El fin próximo del acto es lo mismo que el objeto, y de este recibe su especie" (De malo, q. 2, a. 4, ad 9). Véase también De malo, q. 2, a. 6, ad 9 y a. 7, ad 8.

70 Véase In II Sententiarum, d. 40, q. 1, a. 2, ad 3.

71 “... así como en las cosas naturales lo que es per accidens no constituye la especie, así tampoco en las cosas morales, en las cuales lo que es intentado es per se, mientras que lo que se sigue praeter intentionem es como per accidens" (S. th., II-II, q. 39, a. 1, c.). Véase también S. th., II-II, q. 37, a. 1, c.; II-II, q. 59, a. 2, c.; In VII Ethicorum, lect. 9, n. 1438 (1005); In V Ethicorum, lect. 13, n. 1036 (734); y, usando un sentido de praeter intentionem más cercano al que aquí nos interesa, es decir, como referido a los efectos más o menos previstos pero no queridos ni como fin ni como medio, S. th., II-II, q. 43, a. 3, c.; I-II, q. 72, a. 5, c.; II-II, q. 109, a. 2, ad 2.

72 SPAEMANN (2003a) p. 61.

73 Véase, entre otros, Finnis (1980) pp. 111-125 y SPAEMANN (2003b). 
determinar la bondad o malicia moral de una acción ${ }^{73}$. Y desde el punto de vista jurídico la inviabilidad es, si cabe, más clara aún, pues el Derecho, por sus pretensiones de constituir un orden objetivo, necesita definir especies de acciones que no sean maleables indefinidamente por las consecuencias remotas o los fines ulteriores ${ }^{74}$. Por otra parte, como ha destacado John Finnis, una doctrina de esta naturaleza elimina por su base la posibilidad de que existan derechos humanos absolutos (como el derecho a no ser privado directamente de la vida como medio para ningún fin ulterior, y otros que constituyen la garantía de la dignidad de las personas), ya que, según ella, no hay formas de tratar a un ser humano respecto de las cuales se pueda decir que, cualesquiera que sean las consecuencias, nadie debe ser jamás tratado de esa forma ${ }^{75}$.

También se ha argumentado a favor de la relevancia de la distinción directo/ indirecto apelando a algunas diferencias usualmente aceptadas en prácticas como el arte médico o la guerra. El reconocimiento común de estas diferencias es una señal de que detrás de ellas existe una verdadera significación moral. Este argumento se suele exponer mostrando el contraste que existe entre casos donde el efecto malo es querido como medio y casos donde el efecto malo es meramente previsto. Un ejemplo tomado de la medicina lo provee Philippa Foot. Se presentan en un centro hospitalario seis pacientes agónicos. En un caso, el médico constata que para salvarles la vida necesita administrarles una droga muy escasa. Ahora bien, el primer paciente se salvará con la dosis total con la que cuenta el médico, mientras que los cinco restantes necesitarán un quinto de esa misma dosis. El médico decide repartir la droga entre estos cinco, dejando morir al primero. En un segundo caso, el médico constata que para salvar la vida de los cinco necesita matar al primero y hacer un suero con su cuerpo (o sacarle los órganos para trasplantárselos al resto). El contraste entre ambos casos nos resulta claro: todos juzgamos que en el primero la conducta del médico está justificada, mientras que condenamos su actuar en el segundo. Pero, puesto que en ambas situaciones se trata de cinco vidas contra una, no queda más que aceptar que nuestra diversa evaluación se basa en que atribuimos espontáneamente una relevancia a la distinción directo/indirecto. En efecto, en el segundo caso, a diferencia del primero, el médico ha intentado la muerte de un inocente, ha apuntado hacia ella como parte de un plan, como un medio para alcanzar un fin ${ }^{76}$. Warren Quinn ofrece un ejemplo tomado de las prácticas de la guerra: comúnmente se distingue entre el bombardeo estratégico y el bombardeo aterrorizador. En la primera acción, considerada lícita en el moderno Derecho de guerra, un piloto bombardea una fábrica de armamento del enemigo, con el fin de destruir su capacidad productiva, previendo que morirán algunos civiles que viven cerca. En la segunda, considerada ilícita, el piloto bombardea deliberadamente poblaciones civiles con el fin de desmoralizar al enemigo ${ }^{77}$.

\footnotetext{
74 Para ejemplos de cómo operaría en sede jurídica una doctrina basada en el cálculo o la ponderación, véase RHONHEIMER (1995) p. 291 y DONAGAN (1977) pp. 175-177.

75 Véase FINNIS (1980) pp. 223-226.

76 Véase FOOT (2001) p. 148.

77 Véase QUINN (1989) p. 336.
} 


\section{REQUISITOS DEL PRINCIPIO DEL DOBLE EFECTO: VOLUNTARIEDAD INDIRECTA Y PROPORCIONALIDAD}

\subsection{LA DISTINCIÓN ENTRE EFECTOS INTENTADOS Y EFECTOS COLATERALES}

El primer requisito para la licitud de una acción de doble efecto es que el efecto malo no sea intentado, es decir, que no sea buscado ni como fin ni como medio. En otras palabras, este requisito nos hace presente que no es lícito buscar el efecto malo ni por sí mismo, ni por su utilidad para alcanzar el fin, aunque este fin sea bueno. Así, por ejemplo, si alguien castra a un niño con el propósito de que conserve la dulzura de su voz, no podría apelar al principio del doble efecto para justificar su acción ${ }^{78}$. Si el agente alegara que su acto produce dos efectos, a saber, primero, que el niño es privado de sus órganos genitales, y, segundo, que conserva la dulzura de su voz, de los cuales él intenta aquel y solo acepta este, se le replicaría que, aunque es verdad que su fin es el efecto bueno, también lo es que el efecto malo es precisamente el medio por el que busca conseguir el bueno ${ }^{79}$. El mismo carácter medial tiene la muerte de los civiles en el bombardeo aterrorizador. Por más que su fin remoto sea alcanzar la victoria, la matanza de los inocentes forma parte de aquello que el agente, en su razonamiento práctico, ha juzgado como medio necesario para el éxito del plan. En ambos casos, por tanto, se trata de medios malos que se pretende justificar por un buen fin.

Por el contrario, si reparamos en los ejemplos clásicos de acciones con doble efecto lícitas, vemos que la relación medio-fin entre el efecto malo y el efecto bueno no se verifica. En el ejemplo legado por Vitoria, quien dirige el tormentum hacia la fortaleza enemiga para nada intenta la muerte de los inocentes. Su fin es repeler a los enemigos, y no busca conseguir esto por medio de la muerte de los inocentes. Dichas muertes no le son, por sí mismas, necesarias para el logro de sus propósitos. Más aún, si ellas no se producen el éxito de su acción aumenta. Lo mismo resulta si tomamos el ejemplo de Suárez y lo adaptamos a nuestra realidad. Una mujer embarazada que se somete a una histerectomía o a un tratamiento de quimioterapia para curarse de un cáncer que amenaza su vida y que no puede ser tratado de otra manera, aunque prevé con certeza la muerte del feto, no la busca en modo alguno. Desde luego, su fin no es matar al niño sino curarse del cáncer. Y no se cura porque se muere el feto, sino por la misma histerectomía o por la quimioterapia, de lo que se sigue que la muerte no es un medio, sino más bien un efecto meramente incidental, secundario o colateral ${ }^{80}$.

\footnotetext{
78 Tomo el ejemplo de GrisEZ y SHAW (1988) p. 143, aunque el análisis de estos autores difiere, en parte, del que aquí se ofrece.

${ }^{79} \mathrm{La}$ distinción entre fines y medios es solo relativa, pues únicamente el fin último de toda la vida humana (la felicidad) es puro fin: todos los demás son a la vez fines y medios. Así, en este ejemplo la conservación de la dulzura de su voz es un medio para que el niño pueda cantar bien, y este es un medio para deleitar a los oyentes, etc. No obstante, uno puede hablar de fin último en sentido restringido, para referirse a aquel que preside y da sentido a todo un conjunto de acciones. De este modo se puede decir, por ejemplo, que la victoria es el fin último de la guerra, o que la salud es el fin último de la actividad médica.

${ }^{80} \mathrm{La}$ distinción entre un medio y un efecto colateral no está exenta de dificultades. Por una parte, en la discusión especializada que ha tenido lugar en torno al principio del doble efecto, sobre todo en el ámbito analítico, se traen frecuentemente a colación algunos ingeniosos ejemplos de casos límite que desafían la
} 
El primer requisito también prohíbe que el efecto malo sea intentado como fin secundario o suplementario de la acción. Dicho de otro modo, el agente no debe intentar los dos efectos, sino solo el bueno. Respecto del malo, ha de limitarse únicamente a aceptarlo, permitirlo o tolerarlo como inevitable. Así, si el fin que motiva la acción de quien dispara el tormentum es efectivamente repeler a los agresores, pero junto con esto intenta la muerte de los inocentes porque le ha tomado odio a la nación enemiga, entonces su acción es inmoral por la concurrencia de esta mala voluntad. Una clara señal de que el agente tiene rectitud de intención $-i$. e., que solo se dirige al efecto bueno- es que pondrá los medios tendientes a evitar que se produzca el efecto malo o a disminuir el efecto colateral dañino. A la inversa, una clara señal de que el agente intenta también el efecto malo es que, habiendo podido alcanzar el efecto bueno mediante una acción que no producía el malo, haya elegido sin embargo aquella que lo producía. Volveremos sobre esto más adelante.

Hay que tener en cuenta, con todo, que el análisis de las intenciones secundarias no tiene la misma relevancia para la moral que para el Derecho. Esto se debe a que "el Derecho, no abrazando más que la parte exterior de la justicia, solo atiende a la intención en cuanto se revela o incluye en los actos externos, y la supone buena o mala conforme a la naturaleza de las acciones, a menos que conste lo contrario" ${ }^{81}$. Por consiguiente, “ejecutándose una acción con derecho, la ley no debe entrar en la región de las intenciones; las cuales por sí solas no son materia de la vindicta humana" ${ }^{2}$. Esta no es sino una de las tantas concreciones del principio general de que no corresponde a la ley humana reprimir todos los actos malos: al Derecho le basta con que el objeto del acto

comprensión, por lo general clara, que de ella tenemos (véase, por ejemplo, FOOT, 2001, pp. 145-146 y ANSCOMBE, 2001b, pp. 61-64). A la dificultad que estos casos presentan para trazar dicha distinción se la ha denominado "problema de la proximidad" (véase FisCHER et al., 1993; GALVĀo, 2003; Delaney, 2008). Muchos autores han propuesto criterios para determinar si algo es medio o efecto colateral. Los principales criterios clásicos están expuestos en FinNis (1973) pp. 137-141. En BRATMAN (1999) pp. 139164 se proponen también algunos criterios que hoy en día gozan de gran aceptación. Por otra parte, hay autores que han cuestionado la misma comprensión tradicional de la noción moralmente relevante de "medio". En GRISEZ (1970) p. 87 se sostiene que la identificación de la relación medio-fin -del orden intencional- con la relación causa-efecto - del orden de la naturaleza física- es un error de los intérpretes modernos del principio del doble efecto, que no estaba presente en el uso que de él hace Tomás de Aquino. ${ }^{81}$ FERNÁNDEZ CONCHA (1966a) p. 158.

82 Fernández CONCHa (1966b) p. 326. Dentro de esta idea se enmarca la sólida crítica que formula Rafael Fernández Concha contra el número 6 del artículo 10 del Código Penal chileno, que establece que está exento de responsabilidad criminal el que obra en defensa de la persona y derechos de un extraño solo si, además de cumplir los requisitos generales de la legítima defensa, no ha sido "impulsado por venganza, resentimiento u otro motivo ilegítimo". Según el iusfilósofo chileno, siendo objetivamente justa la acción, no debe ser penada por haberse ejecutado por un motivo ilícito. De lo contrario, habría que castigar igualmente al que por odio a su deudor le demanda el cumplimiento de una obligación exigible en circunstancias apropiadas para arruinarlo, lo que nadie admitiría. Además -agrega en el lugar citado-, hay que tener en cuenta lo siguiente: " $1 .{ }^{\circ}$ No siempre un mal fin corrompe por completo la bondad de la acción. Para que la corrompa, es preciso que dicho fin sea o total, o primario, o gravemente malo; $2 .^{\circ}$ Cuando el mal fin corrompe enteramente la bondad de un acto, este no asume otra malicia que la propia de la intención. Según esto, el que por odio hiere o mata al injusto agresor del prójimo, peca contra la caridad, mas no contra la justicia". 
exterior no sea injusto ${ }^{83}$. De este modo, si la mujer grávida se somete a la quimioterapia con la intención de detener el cáncer, pero al mismo tiempo busca la muerte del niño porque su embarazo no fue deseado, entonces el Derecho debe considerar justificada la acción y no debe castigarla como aborto, a pesar de que la moral condene el desorden de la voluntad de la madre.

\subsection{LA PROPORCIONALIDAD}

El principio del doble efecto no dice que es lícito causar cualquier efecto malo con la única condición de que ese efecto no sea intentado. Los agentes racionales tienen un deber general de evitar el mal para sí mismos y para el prójimo, por lo que, si van a provocar uno a sabiendas, no puede ser por un motivo vano. Por esto, el segundo requisito del principio exige que exista una razón proporcionalmente grave para realizar el acto y aceptar, permitir o tolerar el efecto malo. Del texto de santo Tomás sobre la defensa occisiva se desprende que la proporcionalidad con la que debe cumplir una acción de doble efecto es de dos clases: (i) una proporción entre la acción y su fin, y (ii) una proporción entre el efecto bueno y el efecto malo. La primera consiste en que la acción de la que se sigue el efecto malo debe ser necesaria para alcanzar el efecto bueno. Esto quiere decir que no debe existir otra manera menos perjudicial de obtener este último. Si hay otro curso de acción que permite conseguir el efecto bueno sin causar el malo, o causando un efecto malo de menor importancia, se debe optar por él. Pero esta disponibilidad de cursos de acción alternativos se debe evaluar, desde luego, considerando también la eficacia con que cada uno de ellos dirige hacia el logro del efecto bueno. El segundo tipo de proporción consiste en que el agente debe estar más obligado a conseguir el efecto bueno que a evitar el efecto malo, lo que supone que el bien que se busca con la acción debe ser suficientemente importante en relación con el mal que se tolera ${ }^{84}$. Siguiendo el ejemplo de Suárez, obra en ausencia de este segundo tipo de proporción la mujer encinta que, para curarse de una dolencia leve, toma una medicina riesgosa para la vida de su hijo. Y obra en ausencia del primer tipo de proporción la que la toma para curarse de una

83 "El fin de la ley humana es la tranquilidad temporal de la ciudad (civitatis), al cual llega la ley cohibiendo los actos exteriores en cuanto a los males que pueden perturbar el pacífico estado de la ciudad. En cambio, el fin de la ley divina [y de la ley moral] es conducir al hombre al fin de la felicidad eterna, que es impedido por cualquier pecado, y no solo por los actos exteriores, sino también por los interiores" $(S$. th., I-II, q. 98, a. 1, c.).

${ }^{84}$ Los juristas, por su parte, enfrentados a problemas cuya resolución exige juicios acerca de la proporcionalidad, han seguido criterios muy cercanos a los que proponen los defensores del razonamiento del doble efecto. El Tribunal Constitucional de España, por ejemplo, ha establecido que una determinada medida restrictiva de un derecho fundamental satisface el requisito de la proporcionalidad si cumple las siguientes tres condiciones: $1 .^{\circ}$, que apruebe un juicio de idoneidad, viz., que sea apta para conseguir el objetivo propuesto; $2 .^{\circ}$, que apruebe un juicio de necesidad, en el sentido de que no exista otra medida más moderada para la consecución de tal propósito con igual eficacia; y $3 .^{\circ}$, que apruebe un juicio de proporcionalidad en sentido estricto, esto es, que se deriven de ella más beneficios o ventajas para el interés general que perjuicios sobre otros bienes o valores en conflicto (Tribunal Constitucional, Sentencia n. ${ }^{\circ} 37 /$ 1998, de 17 de febrero de 1998). 
enfermedad grave, pero teniendo a su disposición otra medicina igualmente eficaz e inocua para la vida del niño.

El juicio de proporcionalidad o la ponderación no estriba en una conmensuración o comparación de bienes y males en sentido premoral o físico ${ }^{85}$. De ahí que, si le fuera necesario, una persona se puede defender matando a cinco agresores; y la madre puede someterse a la quimioterapia a pesar de que espere mellizos. Lo decisivo es que para el agente sea más importante, moralmente hablando, conseguir el efecto bueno que evitar el malo. Ahora bien, para este juicio se debe tener en cuenta no solo ni principalmente la importancia relativa de los efectos buenos y los efectos malos en sentido premoral $(v$. gr.: es peor dos muertes que una; es peor una muerte que una mutilación, etc.), sino también cuestiones de derechos y de responsabilidades concretas de evitar ciertos males. Por ejemplo, en su justificación de la defensa occisiva, santo Tomás no dice que nuestra vida sea un bien mayor que la vida del agresor, sino que concede una relevancia fundamental al hecho de que uno está más obligado a velar por su vida que por la vida ajena ${ }^{86}$.

Naturalmente, como son muchos los factores que se deben considerar en una deliberación de este tipo, no es posible establecer a priori y en abstracto qué fines o efectos buenos autorizan a aceptar como efecto colateral determinados males que sería inmoral intentar. Esto solo puede apreciarse prudencialmente atendiendo a las circunstancias del caso concreto. Los teólogos moralistas, con todo, han señalado una serie de criterios generales que deben orientar el juicio acerca de si se cumple o no la proporción entre los efectos. Así, en la sistematización común de estos autores se dice que la causa o razón excusante (i.e., el efecto bueno) debe ser tanto mayor cuanto: (i) más grave es el efecto malo; (ii) más próximo es el efecto malo; (iii) más seguro es que se seguirá el efecto malo; y (iv) mayor es la obligación de impedir el efecto malo ${ }^{87}$. Por el criterio (i), por ejemplo, se debe considerar que un efecto dañino para la sociedad en general tiene más importancia que uno que solo daña a un individuo, y que un efecto que daña a una persona tiene mayor importancia que uno que daña solo bienes materiales. El criterio (ii) se aplica propiamente a los supuestos de cooperación al mal ajeno, en los que el efecto malo no deriva totalmente de la acción del agente, sino que supone la intervención de la acción voluntaria de otro sujeto ${ }^{88}$. El criterio (iii) nos dice, por una parte, que si la probabilidad de que se produzca el efecto malo es baja, mayores razones tendremos para actuar, y, por otra, que mientras más seguro sea que se evitará el efecto malo absteniéndose de actuar, más graves habrán de ser nuestras razones para poner la causa. De acuerdo a esto último, por ejemplo, si la voluntariedad de causar el efecto malo es solo indirecta, el hecho de que ese efecto se vaya a producir tanto en caso de que

\footnotetext{
85 Para una interpretación de esta naturaleza, véase, por ejemplo, MCCORMICK (1976) p. 577.

${ }^{86}$ Véase S. th., II-II, q. 64, a. 7, c.

87 Véase GURY (1850) p. 6; NOLdin (1936) pp. 91-92; LeHMKUHL (1902) p. 21; PrÜMmer (1931) p. 48; LOIANO (1934) p. 47.

${ }^{88}$ El principio del doble efecto también tiene relevancia en el problema de la cooperación al mal, puesto que esta solo es lícita cuando es meramente material y además se cumplen todos los requisitos del principio del doble efecto.
} 
actuemos como de que no actuemos -debido a otra causa que interviene de manera simultánea- es un factor relevante para realizar la acción ${ }^{89}$. Del criterio (iv), en fin, podemos concluir que el que está obligado en virtud de su estado o ex officio a evitar el mal, necesita una razón mayor para causarlo que el que lo está solo por el deber general de caridad. Por ejemplo, una madre necesita una razón más fuerte para realizar una acción de la que se seguirá un mal para su hijo. El mismo criterio nos indica que si se han contraído compromisos previos de no causar ciertos males, menor derecho se tendrá para realizar la acción. Como se puede notar, estos criterios están lejos de reducirse a una mera ponderación entre bienes y males físicos ${ }^{90}$.

Si bien las dos clases de proporción que hemos analizado en los párrafos precedentes se encuentran estrechamente ligadas, la ausencia de cada una de ellas no implica la misma disposición por parte del agente. La falta de proporción entre la acción y su fin es verdaderamente el resultado de una voluntad que intenta el efecto malo, aunque solo lo intente como fin secundario o suplementario de la acción. Consideremos el caso de un militar que debe destruir una fábrica armamentista del enemigo y cuenta con dos tipos de bomba que le permiten alcanzar ese objetivo con igual eficacia, pero una de ellas tiene mayor potencia y destruiría también una población civil cercana. Si el militar, sin otra razón, elige la bomba de mayor potencia, eso no puede ser sino señal de que intentaba la muerte de los civiles, a lo menos como fin secundario o suplementario de su acción. Por el contrario, la falta de proporción entre el efecto bueno y el efecto malo no implica necesariamente que el agente intente el efecto malo. En otros términos, del hecho de que alguien, sin una razón de peso suficiente, realice una acción que previsiblemente causará un efecto malo, no se sigue que ese efecto sea directamente voluntario. Así, una mujer recién encinta que, para tener más posibilidades de ganar un concurso de belleza, se somete a una cirugía que con gran probabilidad producirá la muerte del feto, no tiene por qué intentar esta muerte como fin o como medio. Su fin, que es mejorar su aspecto, es compatible con un anhelo de que el feto se salve, y la muerte de este no es de ninguna manera un medio necesario para la consecución de aquel fin. La mujer, por tanto, obra injustamente no por intentar el efecto malo, sino por causarlo sin una razón de peso suficiente ${ }^{91}$.

\footnotetext{
89 Piénsese, por ejemplo, en el caso de los pilotos estadounidenses que derribaron el cuarto avión secuestrado por los terroristas el 11 de septiembre de 2001. Estando ya claro que la voluntariedad de matar a los pasajeros secuestrados es solo indirecta -sus muertes son el efecto colateral del acto de detener el ataque-, entonces sí cuenta, para determinar si hay o no razón proporcionada para actuar, el hecho de que los pasajeros vayan a morir de todos modos.

${ }^{90}$ Germain Grisez, John Finnis y Joseph Boyle han insistido también en que el requisito de proporcionalidad no se debe interpretar como si exigiera una conmensuración de bienes y males premorales: GRISEZ (1970) pp. 78-79; BOYLE (1980) p. 528; FinNIS (1991b) pp. 81-82. Según estos autores, una vez que se han cumplido las normas morales que prohíben intentar ciertos efectos malos, la determinación acerca de si es o no razonable aceptarlos como efecto colateral se rige por todas las otras normas morales relevantes, especialmente por la "regla de oro", que prohíbe la discriminación o preferencia arbitraria entre las personas.

91 En esto diferimos de Rhonheimer cuando, al hablar del voluntario indirecto, escribe que "[a]lgo solo puede ser no querido en tanto que no es querido ni como medio ni como fin. Pero ello presupone siempre que existe un razón de peso suficiente" (RHONHEIMER, 2000, p. 444. La cursiva de la cita está en el
} 
Esto también permite apreciar que un agente puede actuar de modo más reprochable o culpable por aceptar un efecto colateral sin razón proporcionada que por intentar ese mismo efecto. La madre de nuestro ejemplo puede merecer más reproche que aquella que elige el aborto en caso de violación ${ }^{92}$.

\section{LA RELEVANCIA JURÍDICA DEL PRINCIPIO DEL DOBLE EFECTO}

En las secciones precedentes hemos mostrado que, si bien el principio del doble efecto se desarrolló principalmente en el marco de la teología moral católica, no es una doctrina religiosa, sino un principio moral racionalmente justificado que se apoya en una sólida teoría filosófica sobre el acto humano. En esta sección intentaremos mostrar cómo él también opera, o debería operar, como una guía para el razonamiento jurídico, tanto de los jueces como de los legisladores, en cualquier sistema que entienda la responsabilidad por las acciones de un modo no consecuencialista. Si, por una parte, el principio en cuestión es la vía para resolver con justicia los problemas relativos a la responsabilidad por las acciones con efectos secundarios, y, por otra, estos efectos también pueden ser daños o males significativos para el Derecho, entonces este debe recoger el principio en la medida en que pretenda -como no podría ser de otro modo- estar en consonancia con exigencias de justicia.

Aunque la regla del doble efecto tiene una aplicación amplia, los casos paradigmáticos en los que juristas y filósofos la han invocado son situaciones en las que la acción juzgada causa la muerte de una persona inocente. Esto se debe a que, por la importancia de la vida del inocente, su muerte se ha considerado uno de los ejemplos más patentes de efecto malo que jamás es lícito intentar. En los tres acápites siguientes, nosotros examinaremos la relevancia jurídica del principio usando precisamente casos donde se encuentra involucrada la vida de un inocente. En el cuarto expondremos un uso más amplio, atingente a la protección de los derechos fundamentales en general.

original). El Catecismo de la Iglesia Católica nos da la razón en este punto: "El homicidio involuntario no es imputable moralmente. Pero no se está libre de falta grave cuando, sin razones proporcionadas, se ha obrado de manera que se ha seguido la muerte, incluso sin intención de darla” (n. 2269). Con ello, en efecto, admite que quien realiza sin razón proporcionada una acción de la que se sigue la muerte de una persona, no necesariamente tiene intención de matar. (Asumimos, en esta crítica, que Rhonheimer se refiere a todo tipo de proporción, pues no hace ninguna distinción).

92 En esto diferimos de Finnis cuando afirma que "[l] a forma de voluntariedad implicada en causar a sabiendas efectos colaterales puede bien ser culpable. Pero no puede tener el mismo efecto autoconstitutivo que la forma de voluntariedad que llamamos intentar (elegir)" (FINNIS, 1991b, p. 72). Esta misma idea, en términos de "definición del carácter moral" es mantenida en GRISEZ y BOYLE (1979) p. 388. Al causar a sabiendas un mismo efecto malo, la culpabilidad -y por tanto la autoconstitución de la personalidad o la definición del carácter moral- solo es mayor en la intención que en la aceptación si se considera el asunto ceteris paribus. (Es importante agregar, para la pertinencia de esta objeción, que Finnis, Grisez y Boyle estarían de acuerdo con mi discrepancia respecto de Rhonheimer, como se ve por la crítica que dirigen en FiNNIS et al. (2001) p. 30 a una afirmación similar de Kevin Flannery. 


\subsection{EL PRINCIPIO DEL DOBLE EFECTO EN EL DERECHO INTERNACIONAL DE LA GUERRA}

En la sección 2 hemos visto que la aplicación histórica más importante de la doctrina del doble efecto se refiere al derecho de guerra. Los hoy en día denominados principios de "proporcionalidad" y de "discriminación", desarrollados por los tratadistas del derecho de guerra ${ }^{93}$, son precisamente un reflejo de esta aplicación. En conjunto, ellos disponen que las bajas civiles solo pueden ser aceptadas cuando suceden como efecto colateral de una acción proporcionada de ataque contra un blanco militar, mientras que todo acto de bombardeo aterrorizador contra poblaciones civiles está absolutamente prohibido 94 .

Por esta vía, el razonamiento del doble efecto se encuentra recogido en el Derecho internacional de la guerra. Los principales cuerpos normativos que regulan el ius in bello lo contemplan tanto por vía negativa, es decir, prohibiendo el bombardeo aterrorizador, como por vía positiva, esto es, autorizando el bombardeo estratégico cuando media causa proporcionada. Un ejemplo concreto de esta recepción jurídica lo constituyen los artículos 51.2 y 57.2 del Primer Protocolo de Ginebra (1977). La primera de estas disposiciones prohíbe expresamente el bombardeo de poblaciones civiles y todo acto destinado a sembrar terror. La segunda permite realizar acciones de ataque contra objetivos militares aun cuando se prevea que de ellas pueda seguirse como efecto incidental la muerte de civiles, con tal de que, primero, se tomen todas las medidas tendientes a evitar o minimizar dichas muertes y, segundo, estos daños colaterales no sean excesivos en relación con la ventaja militar que se obtenga del ataque.

\subsection{EL PRINCIPIO DEL DOBLE EFECTO EN LA REGULACIÓN JURÍDICA DE LA EUTANASIA}

Una de las aplicaciones actualmente más importantes del principio del doble efecto es la que tiene lugar en el debate sobre la regulación jurídica de la eutanasia. El principio permite distinguir la eutanasia voluntaria y el suicidio médicamente asistido de actos como la sedación terminal o los tratamientos paliativos del dolor que producen como resultado un acortamiento de la expectativa de vida. Estas últimas acciones, aunque externamente pueden asemejarse a las primeras, difieren significativamente de ellas en su evaluación moral y jurídica. La acción eutanásica (o el suicidio médicamente asistido) tiene por objeto precisamente matar al enfermo con el fin de que deje de sufrir. Es decir, la muerte es buscada como medio para el alivio del dolor. Por el contrario, las otras dos acciones no tienen como propósito privar de la vida al enfermo, sino únicamente aliviar su dolor. Por esto, aunque en ellas el agente prevea que, como efecto colateral, se puede acelerar

\footnotetext{
93 Véase CRUZ Prados (2004) pp. 103-115.

${ }^{4}$ John Rawls, en su tratamiento del ius in bello, sostiene, por el contrario, que la doctrina del doble efecto se opone a los deberes del estadista según el liberalismo político, pues la exención de la emergencia suprema autoriza a suspender el estatuto que protege a los civiles de todo ataque militar directo (véase RAWLS, 2001, pp. 94-105).
} 
o de hecho se acelerará la muerte del paciente, su disposición ante la vida humana es completamente distinta ${ }^{95}$.

De acuerdo a lo anterior, John Finnis señala que, a pesar de su semejanza externa, existe una diferencia moral y jurídica fundamental entre (i) elegir matar a alguien, con el fin de terminar con su dolor, administrándole una droga en el transcurso de tres días para evitar sospechas y (ii) elegir administrarle una droga analgésica con el fin de aliviar su dolor, en una dosis determinada precisamente por la capacidad de la droga para curar el dolor, previendo que esa dosis podría causar la muerte en tres días. Esta segunda acción también sería inmoral y jurídicamente perseguible si falta una razón suficiente para aplicar ese tipo de medicamento (por ejemplo, si el paciente no está agonizando o si existen otras drogas que permitan paliar el dolor sin acortar la vida). Pero, a diferencia de ella, una acción cuyo fin inmediato u objeto sea matar al paciente será siempre un homicidio ${ }^{96}$.

Aunque en algunos casos la distinción entre ambas acciones puede resultar difícil, no debe pensarse que ella depende exclusivamente del conocimiento de la inescrutable intención del agente. Hay muchos factores objetivos que permiten diferenciarlas. Por ejemplo, el tipo de fármacos o narcóticos utilizados y las dosis en que se suministran son un factor que se ha de tener en cuenta. Si se usa un fármaco que no tiene propiedades paliativas, entonces hay una prueba evidente de que la intención es occisiva. Si la droga sirve para aliviar el dolor, todavía habrá que contrastar la dosis suministrada con la historia clínica del paciente y los registros de la forma en que anteriormente ha respondido al tratamiento. Además, puede ser también relevante para este caso considerar la precedencia temporal de los efectos ${ }^{97}$. Si el alivio del dolor precede a la muerte, hay menos razones para pensar que esta fue intentada como un medio para aquel que las que habría en el caso en que la muerte se produce de modo inmediato o instantáneo ${ }^{98}$.

Los ejemplos concretos de la recepción jurídica de la doctrina del doble efecto en esta materia son muchos. Los más significativos pertenecen, como ya hemos dicho, al ámbito del Common Law. En las sentencias de los casos Rodríguez vs. British Columbia (1993) y Vacco vs. Quill (1997), las Supremas Cortes de Canadá y de los Estados Unidos, respectivamente, apelan a la distinción entre intención y efecto colateral para justificar el distinto tratamiento que da el Derecho a la eutanasia o al suicidio asistido,

\footnotetext{
95 Esta aplicación del principio del doble efecto es recogida por el Catecismo de la Iglesia Católica: "El uso de analgésicos para aliviar los sufrimientos del moribundo, incluso con riesgo de abreviar sus días, puede ser moralmente conforme a la dignidad humana si la muerte no es buscada, ni como fin ni como medio, sino solamente prevista y tolerada como inevitable" (n. 2279).

96 Véase FinNis (2004) p. 54.

97 No quiero decir con esto que la precedencia temporal sea un factor que determine, por sí solo, que un efecto fue intentado como medio para el otro. Por el contrario, lo niego. (Los autores que hemos estudiado no exigían, por ejemplo, que en el ataque a la fortaleza enemiga debían morir primero todos los culpables). Más aún, muchos afirman que es lícito atravesar con una espada o una bala al escudo humano con que se cubre el agresor, cuando es la única manera de repeler el ataque de este último: LUGO, De justitia et jure, disp. 10, sec. 5, n. 124; Fernández ConCHA, 1966b, p. 34; MaUsbaCH y ERmeCKe, 1974, p. 222). Solo afirmo que el orden cronológico de los efectos puede ser un elemento que dé luces sobre la intención. 98 Véase MCGEE (2004-2005) pp. 53-54.
} 
por una parte, y a los tratamientos paliativos que aceleran o pueden acelerar la muerte, por la otra. En el Derecho inglés, las principales conclusiones que resultan de la aplicación del principio al problema de la eutanasia se han recogido en el Informe del Comité Selecto sobre Ética Médica de la Cámara de los Lores (1994) ${ }^{99}$. El Informe, elaborado por un Comité presidido por Lord Walton, señala que "el equipo al cuidado de la salud puede aplicar su juicio profesional para permitir que se apliquen crecientes dosis de medicamento (ya sean analgésicos o sedantes) con el fin de proporcionar alivio, incluso si esto abrevia la vida del paciente"100. En este sentido, el Informe constituye un paso trascendente en el abandono progresivo de las tesis utilitaristas por parte de los juristas ingleses. En efecto, el Comité rechaza estas tesis, que en la discusión previa estaban representadas por la opinión de la British Humanist Association. Esta institución calificaba la doctrina del doble efecto como un sofisma, alegando que una acción que produce un resultado bueno y otro malo se justifica solo si el resultado bueno tiene más peso moral que el malo, lo que se establece con independencia de la intención ${ }^{101}$. Por el contrario, el Informe refrenda la relevancia de la intención en su sentido clásico al sostener que la aceleración de la muerte "no es razón para retirar el tratamiento que proporciona el alivio, en tanto que el médico actúe de acuerdo con las prácticas médicas responsables, con el objeto de aliviar el dolor o el estrés, y sin intención de matar" 102 . Igualmente, sale al paso de una crítica común consistente en negar la posibilidad de escrutar y evaluar la intención con la que se realizan las acciones: "Algunas personas pueden pensar que no es fácil evaluar la intención; no obstante, a los jurados se les pide cotidianamente que evalúen la intención en todos los casos que se someten a su consideración, y esto mismo podría hacerse respecto al doble efecto en un caso particular en el que hubiera alguna razón para sospechar que la intención primaria del médico fuera matar al paciente"103. Finalmente, en el Derecho australiano, una enmienda del año 2003 al Código Penal de Queensland (1899) ha establecido que una persona no es penalmente responsable si, como resultado de proporcionar un cuidado paliativo a un paciente terminal, acelera incidentalmente su muerte. A su vez, la enmienda precisa que nada justifica un acto u omisión hecho con la intención de matar a una persona (sección 282A). El acta de enmienda describe este cambio como una "promulgación legal del principio del doble efecto para los cuidados paliativos" ${ }^{104}$.

\subsection{EL PRINCIPIO DEL DOBLE EFECTO Y EL ABORTO}

La distinción entre voluntariedad directa y voluntariedad indirecta funda también la que a su vez existe entre aborto directo y aborto indirecto. En el primero, la muerte del feto entra en el ámbito de la intención, ya sea como fin o como medio. En el

\footnotetext{
${ }^{99}$ Véase Comité Selecto sobre Ética Médica de la CÁmara de los Lores (2004). Las citas las haré siguiendo los números del mismo Informe.

100 Comité Selecto sobre Ética Médica de la Cámara de los Lores (2004), n. 242.

101 Tomo estos datos de FINNIS (2004) p. 52.

102 Comité Selecto sobre Ética Médica de la Cámara de los Lores (2004), n. 242.

103 Comité Selecto sobre Ética Médica de la Cámara de los Lores (2004), n. 243.

104 Véase MCGEE (2004-2005) pp. 46-50.
} 
segundo, la occisión es solo indirecta, esto es, la muerte no se intenta ni como fin ni como medio, sino que solo se acepta como efecto colateral. Esta distinción cobra especial relevancia en todas aquellas situaciones en las que la vida de la madre solo puede salvarse con una acción que involucra la muerte del feto. En esta hipótesis, si la occisión es solo indirecta, la acción se justifica conforme a la regla del doble efecto, pues la salvación de la vida de la madre siempre puede considerarse una razón proporcionalmente importante ${ }^{105}$. Un ejemplo común, ya mencionado, es el de la mujer embarazada que padece cáncer cervical y solo puede librarse de la enfermedad sometiéndose a una histerectomía ${ }^{106}$.

Por consiguiente, una norma que prohíba el aborto de modo absoluto -como también una que de esa manera prohíba el homicidio en general- solo puede referirse a aquel que es causado intencionalmente, es decir, al aborto directo. Esta coherencia se ve, por ejemplo, en la condena absoluta del aborto por parte de Juan Pablo II, la que recae sobre "el aborto directo, es decir, querido como fin o como medio"107; o en la disposición del artículo 119 del Código Sanitario chileno, que prohíbe ejecutar cualquier acción "cuyo fin sea provocar un aborto". En el aborto indirecto, en cambio, la acción no tiene por fin, ni próximo ni remoto, provocar la muerte del nasciturus. Pero de estas afirmaciones no se sigue, por cierto, que cualquier aborto indirecto sea lícito (ya hemos dicho que no lo sería si carece de un motivo proporcionado); ellas solo implican que, como hay algunos abortos indirectos lícitos, la prohibición sobre tal tipo de aborto no puede formularse en términos absolutos.

Si las soluciones de los párrafos precedentes son, por todo lo que hemos expuesto en este trabajo, las adecuadas, entonces el principio del doble efecto es relevante para el razonamiento jurídico, puesto que ellas no se alcanzan necesariamente por recurso a las categorías actuales del Derecho Penal. Esto se debe a que la doctrina penal actual ha reparado solo parcialmente en la significación y el alcance de la distinción directo/ indirecto. Por una parte, algunos autores han visto con claridad que no solo el fin sino también los medios son directamente voluntarios ${ }^{108}$. Pero, por otra, muchos no parecen haber distinguido claramente entre el tipo de voluntariedad implicada en querer un medio (intención) y aquella implicada en la aceptación de un efecto colateral. Esta omisión los ha llevado a considerar el denominado "dolo de las consecuencias seguras" como una forma de dolo directo ${ }^{109}$. Un ejemplo común de dolo de las consecuencias

105 Hay que tener en cuenta además, según los criterios estudiados en la sección 4.2, que en la mayoría de estos casos el feto también morirá si no se realiza la acción salvadora (ya sea una acción terapéutica u otra acción que ponga a la madre a salvo de un peligro).

106 Véase Vermeersch (1933) pp. 600-620. Para otros casos de abortos indirectos y proporcionados, véase BASSO (1993) pp. 393-399. Sobre embarazo ectópico véase KACZOR (2001).

107 Evangelium vitae, n. 62. La cursiva es del original. Véase también el tenor de las palabras de Pablo VI en Humanae vitae, n. 14.

${ }^{108}$ Esto se da por supuesto cuando, al caracterizar el dolo directo como aquel que tiene lugar cuando el autor persigue la realización del delito, precisan que en él es indiferente que el delito sea el único fin que mueve la actuación de agente o que se lo persiga solo como medio para otros fines (véase MIR, 2004, p. 265).

109 Véase CURY (2005) pp. 316-317; MuÑoz CONDE y GARCÍA ARÁN (1996) p. 287. Los autores de esta última obra clasifican el dolo de las consecuencias seguras como una forma de dolo directo, pero lo llaman 
seguras es proveído por Enrique Cury: A, que se ha propuesto matar a B para heredarlo, pone una bomba de tiempo en el avión en que B viajará, previendo que al explotar la bomba durante el vuelo morirán también todos los demás pasajeros ${ }^{110}$. Según este mismo autor, " $[\mathrm{u}] \mathrm{n}$ examen detenido del dolo de las consecuencias seguras conduce a la certeza de que su estructura no difiere de la del dolo directo y de que, por ende, la distinción es arbitraria"111. Para Cury, "[l] o que induce a confusión es que en estas hipótesis hay dos objetivos típicos colocados en relación de medio a fin: la muerte de cada uno de los pasajeros del avión se le aparece a A como el medio necesario para obtener la muerte de B"112. Nosotros pensamos que un examen detenido del caso conduce precisamente a la conclusión contraria: la muerte de cada uno de los pasajeros del avión no es un medio para obtener la muerte de B, sino un efecto colateral (seguro) de la acción de matar a $\mathrm{B}$ haciendo explotar una bomba en el avión ${ }^{113}$. A es, ciertamente, autor del homicidio de todos los pasajeros, pero no por intentar sus muertes como medio, sino por causarlas deliberadamente, como efecto colateral, al realizar una acción ilícita $-y$, por ende, careciendo también de una razón proporcionada-. Que la muerte de los demás pasajeros es un efecto voluntario indirecto se puede apreciar con claridad si se considera un caso semejante en el que la acción juzgada es de suyo lícita. Por ejemplo, si un piloto de la fuerza aérea derriba un avión de pasajeros que ha sido secuestrado por terroristas decididos a estrellarlo contra una alta torre repleta de gente, actúa justificadamente, y no porque en este caso se justifique buscar la muerte de los pasajeros inocentes como medio necesario para el fin de detener el ataque, sino precisamente porque esas muertes no son en modo alguno un medio, sino solo un efecto colateral de un acto lícito de defensa de terceros ${ }^{114}$.

dolo directo de segundo grado, para distinguirlo de aquel en que se intenta el efecto malo, al que llaman dolo directo de primer grado. Como afirman en el lugar citado, su razón para proceder así es que "[l]as diferencias psicológicas no significan necesariamente diferencias valorativas penales". Pero a esto se puede replicar que la distinción directo/indirecto también es (o en algunos casos puede ser) una diferencia moral, y una diferencia moral sí puede, y, a veces, debe, implicar diferencias valorativas penales. Finalmente, hay autores que clasifican el dolo de las consecuencias seguras como dolo indirecto -y, por tanto, como distinto de aquel que exige el legislador cuando usa términos como "maliciosamente"-, pero agregan que tiene lugar respecto de aquel efecto que no es exactamente el deseado por el agente, "sino un medio de alcanzar otro objetivo lícito o ilícito o un efecto concomitante” (GARRIDO MONTT, 2005, p. 102. La cursiva es nuestra).

110 Véase CURY (2005) p. 317.

111 CURY (2005) p. 317.

112 CURY (2005) p. 317. La cursiva es nuestra.

113 Por eso, suponiendo que en el avión solo viajaban B y otro pasajero, es posible que muera B a pesar de salvarse milagrosamente el otro pasajero y el piloto.

${ }^{114}$ Cuando los penalistas ofrecen ejemplos de dolo de las consecuencias seguras proponen siempre casos en los que la acción en sí misma, es decir, considerada con independencia de los malos efectos seguros, ya es ilícita. Si el dolo de las consecuencias seguras supone tal situación, entonces es verdad que distinguirlo del dolo directo resulta superfluo (aunque no arbitrario) para fines punitivos. Pero sucede que cuando los tratadistas exponen el concepto general de dolo de las consecuencias seguras nunca exigen dicha circunstancia para que este se configure. Véase, por ejemplo, CURY (2005) p. 317; MIR (2004) p. 265; MUÑOZ CONDE y GARCÍA ARÁN (1996) p. 287. 
Por todo esto, aun cuando para algunos tratadistas el dolo penal sea un concepto neutro o libre de valoración ${ }^{115}$, y por más que las causales de justificación y de exculpación proporcionen los elementos necesarios para arribar a soluciones justas en los casos concretos, esta importante confusión en la teoría de la acción siempre estará operando como una latente fuente de errores. Volviendo a nuestros casos, de acuerdo con las categorías penales podría concluirse, por ejemplo, que la mujer embarazada que se somete a una histerectomía para curarse de un cáncer incurre en dolo de las consecuencias seguras por haberse representado de ese modo el resultado occisivo. A esto podría replicarse, con todo, que conforme a esas mismas categorías tal caso cae bajo una causal de justificación como el "ejercicio legítimo de un derecho". Y esta solución sería correcta, pero solo per accidens, pues si dicha causal opera con independencia de la clase de voluntariedad implicada en causar el efecto malo, entonces podría invocarse igualmente para justificar la occisión intencional de un inocente, como aquella que tiene lugar en todos los casos de aborto directo buscado por fines terapéuticos.

\subsection{EL PRINCIPIO DEL DOBLE EFECTO EN LA PROTECCIÓN CONSTITUCIONAL DE LOS DERECHOS FUNDAMENTALES}

En las modernas constituciones y declaraciones de derechos, los preceptos que establecen derechos humanos inviolables están formulados de un modo semejante al de las prohibiciones morales absolutas de la tradición clásica ${ }^{116}$. Esto ha favorecido que, en tiempos más recientes, se haya hecho un uso importante del principio del doble efecto en la protección constitucional de los derechos fundamentales. Se trata aquí de una aplicación extensiva, en la que el principio se emplea como criterio para juzgar la conformidad de las leyes u otras disposiciones inferiores con los preceptos constitucionales.

Esta aplicación tiene lugar porque puede suceder que una ley, al propender a la consecución de bienes legítimos, afecte, no obstante, el ejercicio de prácticas que prima facie pudieran considerarse amparadas por un derecho protegido, con lo que surge una situación de doble efecto. En este contexto, los jueces han razonado recurriendo a las mismas categorías recogidas en el principio tradicional: es jurídicamente relevante distinguir entre la intención de la ley y los efectos colaterales que ella pueda provocar. En otros términos, el principio ha servido aquí para distinguir entre leyes que directamente atentan contra el derecho protegido por la norma constitucional y leyes que pueden limitar o restringir ese derecho como efecto colateral de la prosecución de otros fines lícitos. Las leyes del primer tipo son siempre inconstitucionales, mientras que las del segundo no lo son cuando el legislador persigue con ellas un bien suficientemente importante.

Un ejemplo concreto de este modelo de argumentación es el fallo de la Corte Suprema de los Estados Unidos en el caso Employment Division Department of Human

115 Véase CURY (2005) p. 305.

116 Véase FINNIS (1980) pp. 212-213. 
Resources of Oregon vs. Smith (1990). Esta causa se origina cuando el estado de Oregon niega compensación por desempleo a dos personas despedidas por transgredir una disposición estatal que prohibía el uso del alucinógeno "peyote". Los demandantes, que trabajaban como empleados en una clínica de rehabilitación para drogadictos, alegaron que el consumo de dicha droga formaba parte de los ritos propios de su religión, por lo que la ley, al impedírselos, violaba la Primera Enmienda de la Constitución de los Estados Unidos, que prohíbe a la ley inhibir el libre ejercicio de la religión. La Corte sentenció que la disposición no era inconstitucional, pues "si prohibir el ejercicio de la religión [...] no es el objeto [...] sino meramente el efecto incidental de una disposición generalmente aplicable y, por lo demás, válida, la Primera Enmienda no ha sido infringida" (494 U. S. 878 [1990]). El razonamiento de la Corte se basa en la distinción entre leyes que tienen por objeto prohibir el libre ejercicio de la religión y leyes que pueden prohibir incidentalmente (como efecto colateral) ciertas prácticas que se consideran requeridas en el ejercicio de una determinada religión. Solo las leyes del primer tipo caen bajo la prohibición constitucional. Las del segundo no son inconstitucionales cuando el Derecho persigue fines legítimos y suficientemente importantes ${ }^{117}$.

\section{CONCLUSIONES}

El principio del doble efecto, como regla que compendia la relevancia de la distinción entre lo voluntario directo y lo voluntario indirecto, es un principio de razonamiento práctico, filosóficamente fundado, que provee criterios adecuados para evaluar la responsabilidad de un agente en casos de acciones que junto con producir efectos buenos producen también efectos malos. Aunque ha sido desarrollado y estudiado especialmente como principio moral, es apto para ser recogido en el ámbito del Derecho. En efecto, sin perjuicio de que la responsabilidad legal abarca un espectro menor que el de la responsabilidad moral, el Derecho también debe hacer frente a situaciones en las que un efecto malo cuya búsqueda intencional sería castigada por la ley se encuentra vinculado a una acción de suyo lícita que se ordena a alcanzar un bien de importancia proporcionada. En este contexto, el principio puede ser una valiosa ayuda para la deliberación judicial y legislativa. Estas son las razones de que, luego de muchos estudios filosóficos sobre teoría de la acción, el principio haya sido recogido ampliamente por la tradición jurídica anglosajona. Nuestra propuesta es que debería igualmente ser recogido, estudiado y valorado por los juristas del ámbito latino, puesto que, confrontado con otras nociones y distinciones de las que se vale la doctrina actual para tratar problemas semejantes, el principio del doble efecto aporta soluciones mejores y más consistentes.

117 Véase LYONS (2005) pp. 529-531. 


\section{BIBLIOGRAFÍA CITADA}

Alonso, Vicente (1937): Explicación del derecho de defensa según Santo Tomás de Aquino (Roma, Pontificia Universitas Gregoriana).

Anderson, Robert (2007): "Boyle and the Principle of Double Effect", The American Journal of Jurisprudence vol. 52: pp. 259-272.

Anscombe, G. E. M. (2001a): "War and Murder", en: WoOdWard, P. A. (edit.), The Doctrine of Double Effect. Philosophers Debate a Controversial Moral Principle (Notre Dame, University of Notre Dame Press) pp. 247-260.

Anscombe, G. E. M. (2001b): "Medalist's Address: Action, Intention, and 'Double Effect", en: WoOdward, P. A. (edit.), The Doctrine of Double Effect. Philosophers Debate a Controversial Moral Principle (Notre Dame, University of Notre Dame Press) pp. 50-66.

AQuino, Tomás de, Opera omnia. Disponible en: http://www.corpusthomisticum.org/ iopera.html [fecha de consulta: 16 de junio de 2008].

ARistóteles, Opera omnia, en: BARnes, Jonathan (edit.), The complete works of Aristotle (Princeton, Princeton University Press, 1984) 2487 pp.

Austin, John L. (1970): “A Plea for Excuses”, en: Urmson, J. O., y Warnock, G. J. (edits.), Philosophical Papers (Londres, Oxford University Press) pp. 175-204.

AzOR, Juan (1621): Institutionum moralium (Brixiae, Io. Baptistam Bozzolam).

AZPILCUETA, Martín de (1575): Enchiridion sive manuale confessariorum et poenitentium (Lugduni, Guliel. Rovillium).

BÁÑEZ, Domingo (1602): Commentaria in secundam secundae Angelici Doctoris D. Thomae: quibus, quae ad fidem, spem, et charitatem spectant; clarissime explicantur (Venetiis, Petrum Mariam Bertanum).

BÁÑEZ, Domingo (1615): Decisiones de iure et iustitia (Duaci, Petri Borremans).

BAssO, Domingo M. (1993): Nacer y morir con dignidad. Bioética (Buenos Aires, Depalma) $3 .^{\mathrm{a}}$ ed., $504 \mathrm{pp}$.

BECANUS, Martin (1634): De iustitia et iure (Parisiis, Ioannem Iost).

BILluarT, Caroli Renati (1778): Summa S. Thomae hodiernis academiarum moribus accommodata, sive Cursus theologiae (Venetiis, Petri Savioni).

Boyle, Joseph (1980): “Toward Understanding the Principle of Double Effect", Ethics 90: pp. 527-538.

BOyLE, Joseph (1991): "Who is Entitled to Double Effect", The Journal of Medicine and Philosophy 16: pp. 475-494.

Boyle, Joseph (2004): "Medical Ethics and Double Effect: The Case of Terminal Sedation", Theoretical Medicine and Bioethics 25: pp. 51-60.

Bratman, Michael (1999): Intention, Plans, and Practical Reason (Stanford, Leland Stanford Junior University) 200 pp.

Cavanaugh, Thomas (1997): "Aquinas's Account of Double Effect", The Thomist 61: pp. 107-121.

Cavanaugh, Thomas (2006): Double-Effect Reasoning: Doing Good and Avoiding Evil (Oxford, Oxford University Press) 220 pp. 
Comité Selecto sobre Ética Médica de la CÁmara de los lores (2004): “Extracto del Informe del Comité Selecto sobre Ética Médica de la Cámara de los Lores", en: KEOWN, John (edit), La eutanasia examinada. Perspectivas éticas, clinicas y legales (traduc. E. Torres, México, Fondo de Cultura Económica) pp. 139-168.

Cruz Prados, Alfredo (2004): La razón de la fuerza. Concepto y justicia de la guerra (Madrid, Pearson) 300 pp.

Cury, Enrique (2005): Derecho Penal. Parte general (Santiago, Universidad Católica de Chile, 7. ${ }^{\mathrm{a}}$ ed.) $812 \mathrm{pp}$.

Delaney, Neil (2008): “Two Cheers for "Closeness": Terror, Targeting and Double Effect”, Philosophical Studies 137: pp. 335-367.

Donagan, Alan (1977): The Theory of Morality (Chicago, The University of Chicago Press) $278 \mathrm{pp}$.

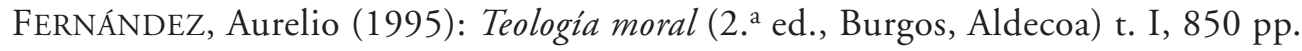

FERNÁNDEZ CONCHA, Rafael (1966a): Filosofía del derecho o derecho natural (Santiago, Editorial Jurídica de Chile, 3. a ed.) t. I, 503 pp.

FERnÁNDEZ CONCHA, Rafael (1966b): Filosofía del derecho o derecho natural, t. II (3. ${ }^{\text {a }}$ ed., Santiago, Editorial Jurídica de Chile) 565 pp.

FInNIS, John (1973): “The Rights and Wrongs of Abortion: A Reply to Judith Thomson", Philosophy and Public Affairs 2: pp. 117-145.

FINNIS, John (1980): Natural Law and Natural Rights (Oxford, Clarendon Press) 425 pp.

FINNIS, John (1991a): "Intention and Side Effects", en: FreY, R. G., y MORRIS, C. W. (edits.), Liability and Responsibility: Essays in Law and Morals (Cambridge, Cambridge University Press) pp. 32-64.

FInNIS, John (1991b): Moral Absolutes: Tradition, Revision, and Truth (Washington D. C., The Catholic University of America Press) 113 pp.

FINNIS, John (2004): "Un argumento filosófico contra la eutanasia”, en: KEOWN, John (edit), La eutanasia examinada. Perspectivas éticas, clinicas y legales (traduc. E. ToRRES, México, Fondo de Cultura Económica) pp. 49-63.

FINNIS, John; GRISEZ, Germain, y BOYLE, Joseph (2001): “'Direct' and 'Indirect': a Reply to Critics of our Action Theory”, The Thomist 65: pp. 1-44.

FISCHER, John; RAVIZZA, Mark, y COPP, David (1993): "Quinn on Double Effect: The Problem of 'Closeness"”, Ethics 103: pp. 707-725.

FOOT, Philippa (2001): "The Problem of Abortion and the Doctrine of the Double Effect”, en: Woodward, P. A. (edit.), The Doctrine of Double Effect. Philosophers Debate a Controversial Moral Principle (Notre Dame, University of Notre Dame Press) pp. 143-155.

Galvão, Pedro (2003): "Duplo Efeito: O Problema da Proximidade”, en: Falguera, J. L. et alii (edits.), Palabras y pensamientos: una mirada analitica (Santiago de Compostela, Universidad de Santiago de Compostela) pp. 419-442.

GARCÍA DE HARO, Ramón (1992): La vida cristiana. Curso de teología moral fundamental (Pamplona, Eunsa) 849 pp.

Garrido Montt, Mario (2005): Derecho Penal. Parte general II. Nociones fundamentales de la teoría del delito (Santiago, Editorial Jurídica de Chile 4. ${ }^{\mathrm{a}}$ ed., ) 478 pp. 
GÉNICOT, Eduardus (1909): Theologiae moralis institutiones (Bruxellis, Dewit, 6. ${ }^{\mathrm{a}}$ ed.) t. I, $630 \mathrm{pp}$.

GHoOs, J. (1951): "L'acte a double effet. Étude de théologie positive", Ephemerides Theologicae Lovanienses 27: pp. 30-52.

GRISEZ, Germain (1970): “Toward a Consistent Natural-Law Ethics of Killing”, The American Journal of Jurisprudence 15: pp. 64-96.

GriseZ, Germain, y BOYLE, Joseph (1979): Life and Death with Liberty and Justice. A Contribution to the Euthanasia Debate (Notre Dame, University of Notre Dame Press) $521 \mathrm{pp}$.

GriseZ, Germain, y SHAW, Russell (1988): Beyond the New Morality. The Responsibilities of Freedom (Notre Dame, University of Notre Dame Press, 3. $\left.{ }^{\mathrm{a}} \mathrm{ed}.\right) 256 \mathrm{pp}$.

GURY, Joanne Petro (1850): Compendium theologiae moralis (Lugduni-Parisiis, Perisse) t. I.

GurY, Joannis Petri, y FERrERES, Joannis (1906): Compendium theologiae moralis (hispana, Barcinone, Subirana Fratres, 3. ${ }^{\text {a ed.) }}$ t. I.

IGLESIA CATÓlICA: Catecismo de la Iglesia Católica (Roma, 1992).

JUAN PABLO II: Evangelium vitae (Roma, 1995).

KACZOR, Christopher (1998): "Double-Effect Reasoning from Jean Pierre Gury to Peter Knauer”, Theological Studies 59: pp. 297-316.

KACZOR, Christopher (2001): "Moral Absolutism and Ectopic Pregnancy", The Journal of Medicine and Philosophy 26: pp. 61-74.

LeHMKuHL, Augustino (1902): Theologia moralis, t. I (10. a ed., Friburgi, Herder).

LESSIO, Leonardo: De iustitia et iure (Lugduni, Ludovici Prost, 1622).

LigOrIO, Alfonso de: Theologia moralis (Romae, Remondinianis, 1767).

LOIANO, Seraphinus a (1934): Institutiones theologiae moralis, t. I (Taurini, Marietti).

LONG, Steven (2003): "A Brief Disquisition Regarding the Nature of the Object of the Moral Act According to St. Thomas Aquinas", The Thomist 67: pp. 45-71.

LONG, Steven (2007): The Teleological Grammar of The Moral Act (Naples, Sapientia Press) $146 \mathrm{pp}$.

LugO, Juan de: Disputationes scholasticae et morales. De justitia et jure (Parisiis, Ludovicum Vivés, 1893).

LYONS, Edward (2005): "In Incognito. The Principle of Double Effect in American Constitutional Law”, University of Florida Law Review 57: pp. 469-563.

Mangan, Joseph (1949): "An Historical Analysis of the Principle of Double Effect", Theological Studies 10: pp. 41-61.

MATTHEWS, Gareth (1999): "Saint Thomas and the Principle of Double Effect", en: MacDonald, S., y STUmp, E. (edits.), Aquinas's Moral Theory. Essays in Honor of Norman Kretzmann (Ithaca, Cornell University Press) pp. 63-78.

Mausbach, Joseph, y ERMECKE, Gustav (1971): Teología moral católica, t. I (traduc. M. GARCía, Pamplona, Eunsa).

MAUSBACH, Joseph, y ERMECKE, Gustav (1974): Teología moral católica, t. III (traduc. M. García, Pamplona, Eunsa). 
MCCORMICK, Richard (1976): "El principio del doble efecto" (traduc. A. GOÑI), Concilium 120: pp. 564-582.

MCGEE, Andrew (2004-2005): "Double Effect in the Criminal Code 1899 (QLD): A Critical Appraisal", Queensland University of Technology Law and Justice Journal 4: pp. 46-57.

MerkelbaCH, Benedictus (1935): Summa theologiae moralis (Parisiis, Desclée de Brouwer) t. I.

Mir, Santiago (2004): Derecho Penal. Parte general (Barcelona, Reppertor, 7. a ed.) 781 pp.

Molina, Luis de (1614): De iustitia et iure (Coloniae Agrippinae, Hermanni Mylil).

Muñoz Conde, Francisco, y García Arán, Mercedes (1996): Derecho Penal. Parte general (Valencia, Tirant lo Blanch, 2. ${ }^{\text {a }}$ ed.) 549 pp.

NAVARRA, Pedro de (1593): De ablatorum restitutione in foro conscientiae (Lugduni, Iuntarum).

Noldin, Hieronymus (1936): Summa theologiae moralis (Ratisbonae, Rauch, 24. ${ }^{a}$ ed.) t. I. PABLO VI (1968): Humanae vitae (Roma).

PoInsot, Juan (1931): Cursus theologicus (Parisiis, Desclée et sociorum).

PRÜMmer, Dominicus M. (1931): Manuale theologiae moralis (Friburgo, Herder, 6. ${ }^{a}$ ed.) t. I.

QuinN, Warren (1989): "Actions, Intentions, and Consequences: The Doctrine of Double Effect", Philosophy and Public Affairs 18: pp. 334-351.

ReICHBERG, Gregory (2005): “Aquinas on Defensive Killing: A Case of Double Effect?”, The Thomist 69: pp. 341-370.

RHONHEIMER, Martin (1995): "Intentional Actions and the Meaning of Object: A Reply to Richard McCormick", The Thomist 59: pp. 279-311.

RHONHEIMER, Martin (2000): Ley natural y razón práctica. Una visión tomista de la autonomía moral (traduc. M. EsPIÑA, Pamplona, Eunsa) 576 pp.

Rossi, Leandro (1978): "Doble efecto (principio del)", en: Rossi, L., y VALSECCHI, A. (edits.), Diccionario enciclopédico de teología moral (3. ${ }^{\mathrm{a}}$ ed., Madrid, Paulinas) pp. 233-247.

RAWLS, John (2001): The law of peoples (Cambridge, Harvard University Press) 199 pp.

SÁNCHEZ, Tomás: De sancto matrimonii sacramento disputationum (Norimbergae, J. C. Lochneri, 1706).

Soto, Domingo de: De iustitia et iure (edición bilingüe de Marcelino GONZÁLEZ, Madrid, Instituto de Estudios Políticos, 1967-1968).

SpaEmann, Robert (2003a): "Acciones concretas", en: SPAEMANn, Robert, Limites. Acerca de la dimensión ética del actuar (traduc. J. FERnÁndeZ y J. MARdOMingo, Barcelona, Eiunsa) pp. 51-64.

SPAEMANN, Robert (2003b): "Sobre la imposibilidad de una ética teleológica en sentido universal”, en: Spaemann, Robert, Limites. Acerca de la dimensión ética del actuar (traduc. J. FernándeZ y J. MARdomingo, Barcelona, Eiunsa) pp. 185-204.

SUÁREZ, Francisco: Commentaria in secundam secundae divi Thomae, scilicet de fide, de spe et de charitate disputationes (Parisiis, Ludovicum Vivés, 1858). 
Toledo, Francisco de (1869): In Summam theologiae S. Thomae Aquinatis enarratio (Romae, Marietti-Palmé).

VÁZQUEZ, Gabriel (1617): Opuscula moralia (Alcalá de Henares, Ioannis Gratiani).

VermeErsCH, Arthurus (1922): Theologiae moralis. Principia, responsa, consilia (ParisiisBrugis, Universidad Gregoriana) t. I.

VermeErsch, Arturo (1933): "Avortement direct ou indirect. Réponse au T. R. P. Gemelli, O. F. M.”, Nouvelle Revue Thèologique 60: pp. 600-620.

Vío, Tomás de (1773): Commentarium in Summa S. Thomae, en: AQUINATIS, Thomae, Summa theologica, cum commentariis Thomae de Vio Card. Cajetani, et elucidationibus litteralibus P. Seraphini Capponi a Porrecta (Roma, s./ed., 1773).

VITORIA, Francisco de: Commentarium in secundam secundae (Madrid, Asociación Francisco de Vitoria, 1934).

VITORIA, Francisco de: De indis posterior, sive De jure belli hispanorum in barbaros (edición bilingüe de Luis GetinO, Madrid, La Rafa, 1934). Solo me aparto excepcionalmente de esta traducción.

Vitoria, Francisco de: De homicidio (edición bilingüe de Luis GetinO, Madrid, La Rafa, 1934).

ZalBA, Marcellino (1952): Theologiae moralis summa (Madrid, Biblioteca de Autores Cristianos) t. I, 965 pp. 
